\title{
Effect of Wheat Roots Infected with the Pathogenic Fungus Gaeumannomyces graminis var. tritici on Gene Expression of the Biocontrol Bacterium Pseudomonas fluorescens Pf29Arp
}

\author{
Matthieu Barret, ${ }^{1}$ Pascale Frey-Klett, ${ }^{2}$ Anne-Yvonne Guillerm-Erckelboudt, ${ }^{1}$ Morgane Boutin, ${ }^{1}$ \\ Gregory Guernec, ${ }^{3}$ and Alain Sarniguet ${ }^{1}$ \\ ${ }^{1}$ INRA, Agrocampus Rennes-Université Rennes 1, UMR1099 BiO3P 'Biologie des Organismes et des Populations appliquée \\ à la Protection des Plantes', 35653 Le Rheu, France; ${ }^{2}$ INRA, UMR 1136 INRA-Nancy Université 'Interactions \\ Arbres/Microorganismes', 54280 Champenoux, France; ${ }^{3}$ INRA Scribe, IFR140, Campus de Beaulieu, 35042 Rennes, \\ France
}

Submitted 16 May 2009. Accepted 6 July 2009.

Traits contributing to the competence of biocontrol bacteria to colonize plant roots are often induced in the rhizosphere in response to plant components. These interactions have been studied using the two partners in gnotobiotic systems. However, in nature, beneficial or pathogenic fungi often colonize roots. Influence of these plant-fungus interactions on bacterial behavior remains to be investigated. Here, we have examined the influence of colonization of wheat roots by the take-all fungus Gaeumannomyces graminis var. tritici on gene expression of the biocontrol bacterium Pseudomonas fluorescens Pf29Arp. Bacteria were inoculated onto healthy, early $G$. graminis var. tritici-colonized and necrotic roots and transcriptomes were compared by shotgun DNA microarray. Pf 29Arp decreased disease severity when inoculated before the onset of necrosis. Necrotic roots exerted a broader effect on gene expression compared with early G. graminis var. tritici-colonized and healthy roots. A gene encoding a putative type VI secretion system effector was only induced in necrotic conditions. A common pool of Pf 29Arp genes differentially expressed on G. graminis var. tritici-colonized roots was related to carbon metabolism and oxidative stress, with a highest fold-change with necrosis. Overall, the data showed that the association of the pathogenic fungus with the roots strongly altered Pf 29Arp adaptation with differences between early and late $G$. graminis var. tritici infection steps.

The rhizosphere, usually defined as the area influenced by the plant root system, provides a nutrient-rich environment for microorganisms. However, in the soil environment, roots are commonly colonized with filamentous fungi that may be beneficial or pathogenic in nature (de Boer et al. 2005). The influence of roots and fungi creates an environment that differs from the rhizosphere of an uninfected plant. For example, the mycorrhizosphere, which is the area influenced by both roots and mycorrhizal fungus, is colonized by a modified bacterial

Corresponding author: A. Sarniguet; Telephone: +3322348 51 94; Fax: +33 2234851 80; E-mail: alain.sarniguet@ rennes.inra.fr

* The $\boldsymbol{e}$-Xtra logo stands for "electronic extra" and indicates three supplemental tables and one supplemental figure are published online. community compared with the rhizosphere (Andrade et al. 1997; Frey-Klett et al. 2005). A similar effect occurs in the pathorhizosphere, as the result of roots infected with a pathogenic fungus (Chapon et al. 2002). Indeed, the healthiest plant may not provide the greatest benefits in terms of fitness for many rhizobacteria (Denison et al. 2003). Lesions caused by soil fungal pathogens can increase nutrient availability in the rhizosphere due to leakage from damaged root tissues (Curl and Truelove 1986) leading to the selection of specific rhizobacteria community (Sanguin et al. 2008).

Certain rhizobacteria exert positive effects on plant fitness by reducing fungal soilborne diseases and improving plant growth. Such bacteria belong to the plant-growth-promoting rhizobacteria (PGPR) group, which includes many genera, such as Pseudomonas (Kloepper et al. 1980). The main biocontrol mechanisms are active exclusion of pathogenic fungi from the rhizosphere (Haas and Defago 2005) and induction of plant disease resistance (van Loon et al. 1998). The efficiency of biocontrol bacteria depends not only on their direct and indirect fungistatic or fungicidal activity but also on their root colonization capacity, which contributes to rhizosphere competence (Lugtenberg et al. 2001). Various bacterial functions, such as chemotaxis (de Weert et al. 2002), motility (Simons et al. 1996; Ramos-Gonzalez et al. 2005), cell attachment (Buell and Anderson 1992; Rodriguez-Navarro et al. 2007), growth (Simons et al. 1997; Rainey 1999), microcolony formation (Chin-A-Woeng et al. 1997; Bloemberg et al. 2000), and stress resistance (Sarniguet et al. 1995; Matilla et al. 2007) were proven to be involved in rhizosphere competence and in improvement of root colonization. Root exudates such as organic acids, sugars, and amino acids influence the ability of microbial strains to colonize the roots (Mark et al. 2005; Kamilova et al. 2006a). However, pathogenic fungi modify the amounts and composition of root exudates components (Kamilova et al. 2006b). Furthermore, fungi are also expected to play a major role in bacterial growth and movement in soil (Tarkka et al. 2009); some hyphal exudates induce bacterial chemotaxis and growth (de Weert et al. 2004) and hyphae can act as a surface to promote movement of soil bacteria (Kohlmeier et al. 2005). For example, the biocontrol strain Pseudomonas fluorescens WCS365 preferentially colonizes hyphae of the pathogenic fungus Fusarium oxysporum f. sp. radicis-lycopersici in the tomato rhizosphere (Bolwerk et al. 2003). However, none of 
these studies have explored the impact of pathogenic fungi or fungal-infected roots on the molecular determinants involved in root colonization and biocontrol efficiency of PGPR.

The decrease of take-all disease severity after several years of wheat monoculture is related to the selection of biocontrol rhizobacteria, including pseudomonads (Cook and Rovira 1976; Sanguin et al. 2008). This phenomenon, called take-all decline, needs a severe outbreak caused by the pathogenic fungus Gaeumannomyces graminis var. tritici. An effect of roots colonized by $G$. graminis var. tritici on the composition and the amount of biocontrol pseudomonad populations is observed (Chapon et al. 2002). The presence of $G$. graminis var. tritici and the necrotic root lesions caused by G. graminis var. tritici drive the development of populations of certain types of pseudomonad (Barnett et al. 1999). For instance, the strain Pf29Arp, which belongs to a specific repetitive extragenic palindrome polymerase chain reaction (REP-PCR) cluster and is an efficient wheat root colonizer in the absence of $G$. graminis var. tritici, becomes dominant toward indigenous pseudomonads in the presence of $G$. graminis var. tritici and decreases take-all severity when inoculated in soil (Sarniguet et al. 1997; Chapon et al. 2002). Three mechanisms of biocontrol were suggested: environmental acidification through gluconic acid production, induced systemic plant resistance, and change in microbial community composition (Sarniguet et al. 2006). In

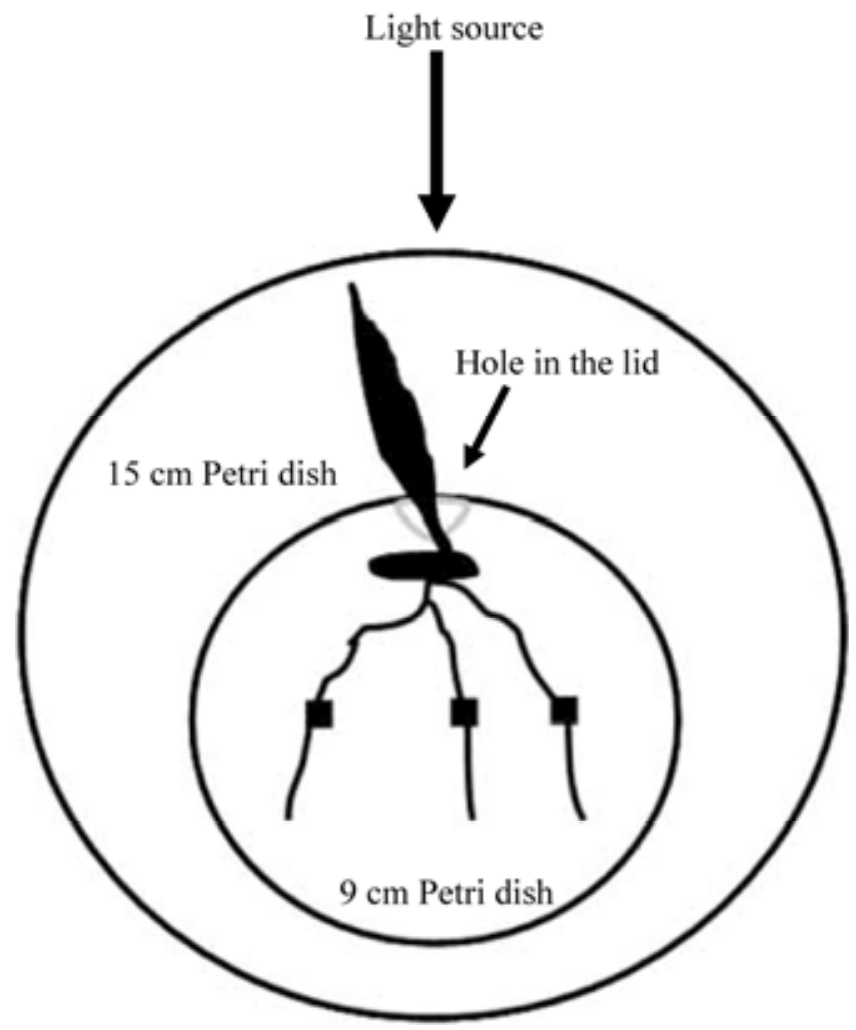

Fig. 1. Scheme of the bioassay used to arrange tripartite interaction between wheat roots, the pathogenic fungus Gaeumannomyces graminis var. tritici strain IV-26/00 and the bacterial strain Pseudomonas fluorescens Pf 29Arp. Roots were placed on water agar of a 9-cm petri dish containing water agar (30 $\left.\mathrm{g} \mathrm{liter}^{-1}\right)$. A hole was previously made at the border and also in the lid of the dish to let the root grow gnotobiotically inside and to allow the leaf to grow outside. Fungal plugs (ם) of strain $G$. graminis var. tritici IV-26/00 were placed on each principal roots at $3 \mathrm{~cm}$ from the seed and removed after 2 days. Pf 29Arp (10 6 cells) were deposited on each root at 3 $\mathrm{cm}$ from the seed. Each dish was closed with Parafilm $\mathrm{M}$ and surrounded with an aluminum sheet to make an opaque environment. Then dishes were placed inside a larger $15-\mathrm{cm}$ sterile dish to retain a sterile environment. The combined plates were then incubated at $15^{\circ} \mathrm{C}$ with an alternating cycle of $14 \mathrm{~h}$ of light and $10 \mathrm{~h}$ of darkness. previous work, the influence of $G$. graminis var. tritici alone on Pf 29Arp gene expression was assessed during a commensal in vitro interaction (Barret et al. 2009). However, the influence of roots infected with pathogenic fungus on bacterial gene expression remains unknown.

The aim of the present work was to assess the effect of wheat roots infected with $G$. graminis var. tritici on gene regulations of the biocontrol strain P. fluorescens Pf29Arp. For this purpose, Pf29Arp was inoculated in three different environments: healthy roots, early colonized roots, with G. graminis var. tritici and necrotic roots. Bacterial transcriptome was compared with the use of a Pf29Arp genomic shotgun array (Barret et al. 2009).

\section{RESULTS}

\section{Colonization patterns of wheat roots} by $G$. graminis var. tritici.

To describe the infection process of G. graminis var. tritici in the in vitro bioassay (Fig. 1), we performed a time-course measure of size of necrotic lesions (Fig. 2) and a simultaneous microscopic observation of the fungal mycelium after staining with Chlorazol Black E (Fig. 3). Early root colonization and infection events were observed on 7-day-old wheat seedlings inoculated with the strain $G$. graminis var. tritici IV-26/00. Two days after inoculation with G. graminis var. tritici (day 9), fungal plugs were removed and hyphae were observed on the root surface (Fig. 3G). At day 9, no necrosis symptoms were observed but the pathogen had already penetrated the host tissue through the root epidermis because hyphae were present inside some root cortex cells (Fig. 3B). At day 10, small 1-mm necroses were visible (Fig. 2). At day 11, necrosis size reached $3 \mathrm{~mm}$ (Fig. 2) and hyphae were present in all root cortex cells (Fig. 3F). At day 12, necrosis extended to $6 \mathrm{~mm}$ and hyphae of G. graminis var. tritici were more abundant in the cortex cells and caused host tissue alteration. The hyphae also passed the endodermis and entered the stele tissue of the roots. At day 14, necrosis reached $10 \mathrm{~mm}$, the pathogen completely colonized the stele tissue (Fig. 3D), and G. graminis var. tritici hyphae were also observed in xylem vessels (Fig. 3E). At this stage, the massive colonization of the roots caused marked cells degradation.

Effects of Pf 29Arp on G. graminis var. tritici pathogenesis.

The influence of Pf29Arp on G. graminis var. tritici pathogenesis in the in vitro bioassay was assessed by severity (corresponding to the necrosis length of diseased roots). Two Pf 29Arp inoculation treatments, one at day 9 (early Pf29Arp treatment) before onset of necrosis (E) and a second at day 12 (late Pf29Arp treatment) after onset of necrosis (N) were compared with the G. graminis var. tritici inoculation treatment without bacteria at the same corresponding stages (Fig. 4).

At day 11, disease severity of necrotic roots was not significantly different in G. graminis var. tritici control (mean necrosis length of $2.3 \pm 0.4 \mathrm{~mm})$ and early Pf29Arp treatments $(0.8 \pm$ $0.3)$. At day 12 and 14 , severity was not significantly different between $G$. graminis var. tritici control $(4.6 \pm 0.6 ; 10.3 \pm 0.5)$ and late $(4.6 \pm 0.6 ; 9.0 \pm 0.7)$ Pf 29Arp treatments. However, at these same days, severity was significantly lower for early Pf29Arp treatment $(1.8 \pm 0.6 ; 3.1 \pm 0.8)$ compared with the two other treatments $(P=0.05)$.

Disease incidence (expressed as percentage of diseased roots) was also assessed (data not shown). At day 11 and 12, 69.6 and $78.3 \%$, of $G$. graminis var. tritici control roots had necrosis, respectively, while incidence dropped significantly to $30.4 \%$ for early Pf29Arp treatment according to confidence interval (IC) $\left(P=0.05 ; \Delta=39.1, \mathrm{IC}_{11 \mathrm{~d}}[1.7,77.6] ; \Delta=47.8\right.$, 
Day 0

Day 2

Day 7
Seed surface sterilization and transfer in LPGA plates

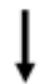

Seminal roots transfer in MS media<smiles>[13CH3]</smiles>

Roots transfer in water-agar

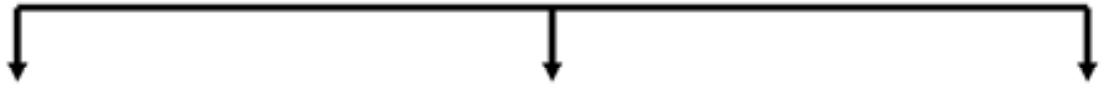

Healthy root

Early Ggt $\quad$ Necrotic root
root colonization

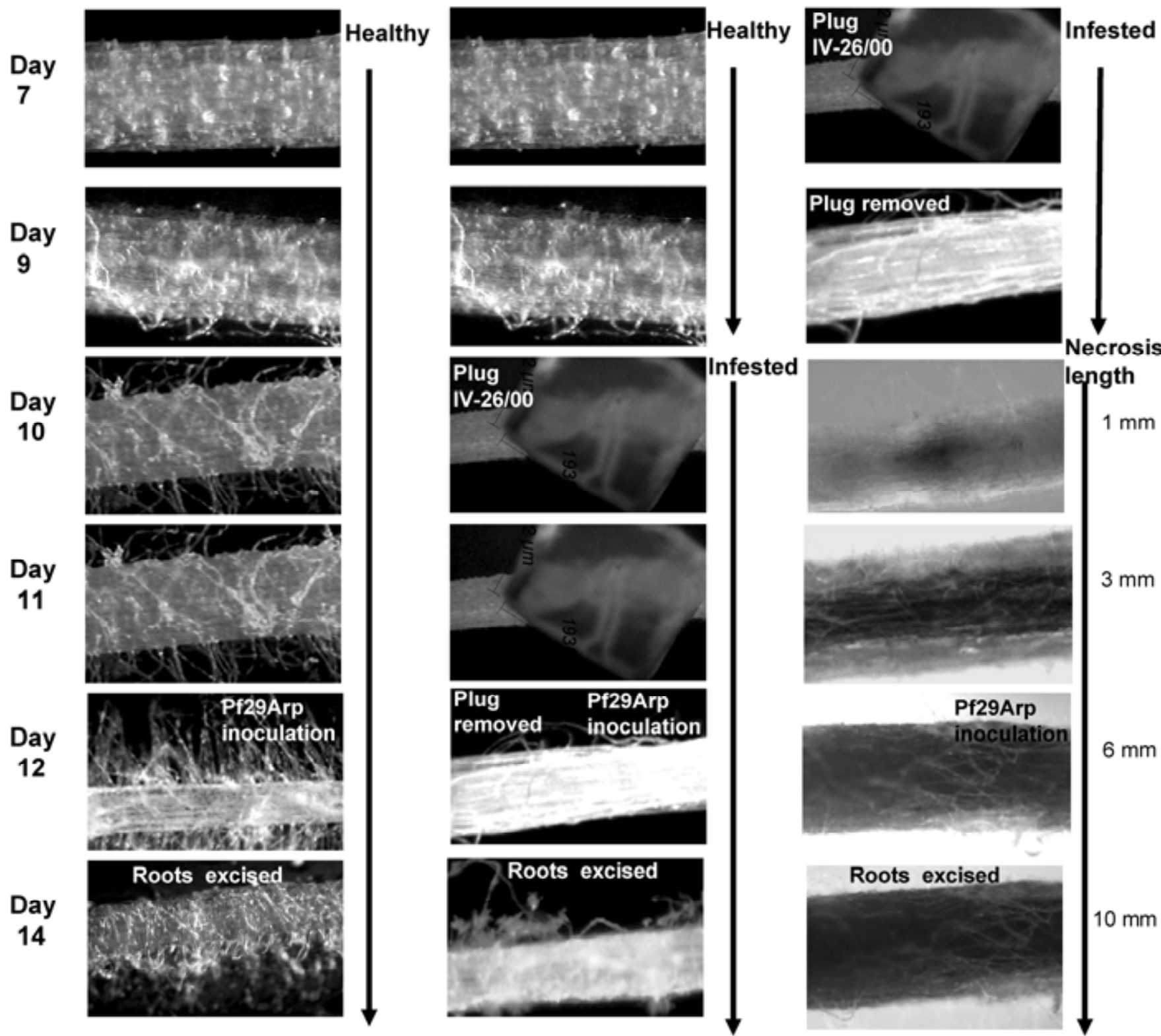

Fig. 2. Time-course of Gaeumannomyces graminis var. tritici infection of wheat roots. Roots were observed under a binocular microscope at day $7,8,9$, 10 , 11, 12, and 14. Plugs cut from the growing margin of a $G$. graminis var. tritici IV-26/00 culture were inoculated at either day 7 or day 10 on roots and removed 2 days later. At day 12, $10^{6}$ cells of Pseudomonas fluorescens Pf 29Arp were inoculated on healthy, early G. graminis var. tritici-colonized or necrotic roots, respectively. At day 14, roots were excised and bacteria were harvested. Length of necrosis was measured with the Archimed software (Microvision instruments, Evry, France). 
$\left.\mathrm{IC}_{12 \mathrm{~d}}[11.4,84.3]\right)$. At day $14,100 \%$ of $G$. graminis var. tritici control roots had necrosis while incidence decreased significantly to $78.3 \%$ for early Pf 29 Arp treatment $\left(\Delta=21.7, \mathrm{IC}_{14 \mathrm{~d}}\right.$ $[4.5,39.0])$. However, microscopic observation of roots colonized with both $G$. graminis var. tritici and Pf29Arp at day 12 and 14 revealed few hyphae inside the cortical cells for nonnecrotic roots (data not shown). On the contrary, late Pf 29Arp treatment had no significant effect on disease incidence compared with G. graminis var. tritici control roots.

\section{Pf 29Arp colonization patterns.}

P. fluorescens Pf29Arp growth was monitored by dilution plating (Fig. 5). Although Pf29Arp inoculation was made from the same bacterial suspension, the number of CFU per centimeter of roots at time-point 0 (20 min after Pf29Arp inoculation) differed significantly $(P=0.05)$ for necrotic roots $(\mathrm{N})$ when compared with healthy $(\mathrm{H})$ and early $G$. graminis var. tritici-colonized roots (E). During the first $24 \mathrm{~h}$, the population density increased similarly for $\mathrm{N}$ and $\mathrm{H}$ treatments with a respective $\log _{10}$ bacterial multiplication rate of $1.0( \pm 0.1)$ and $1.2( \pm 0.2)$ and was significantly (four times) less with a rate of $0.3( \pm 0.1)$ in treatment E. Population density of $\mathrm{N}$ and $\mathrm{E}$ treatments still increased between 24 and $48 \mathrm{~h}$ with a bacterial multiplication rate of $0.7( \pm 0.1)$ and $0.6( \pm 0.1)$, respectively, whereas population density of $\mathrm{H}$ treatment remained constant.
At $24 \mathrm{~h}$ for $\mathrm{H}$ and at $48 \mathrm{~h}$ for $\mathrm{E}$ and $\mathrm{N}$, population amount reached approximately $5 \times 10^{6}$ cells for the three treatments. After $48 \mathrm{~h}$, cells density remained constant for the three treatments until $96 \mathrm{~h}$, with only a slight decrease observed for treatment $\mathrm{E}$ between 72 and $96 \mathrm{~h}(-0.31 \pm 0.1)$.

\section{Microarray hybridization.}

Pairs of Pf29Arp RNA samples were extracted from healthy roots $(\mathrm{H})$, roots early colonized with $G$. graminis var. tritici without any necrosis (E), and necrotic roots (N) 2 days after bacterial inoculation. After RNA amplification, the corresponding cDNA were then hybridized to different microarray slides following a loop design. Three independent biological replicates, each containing two technical replicates (dye-swap), were performed for each experiment.

Range of RNA amplification bias effects were examined in determining the number of genes over- or under-repressed in amplified compared with unamplified expression profiles (Supplementary Fig. S1). Using an arbitrary $\log _{2} 0.3$-fold cutoff, we detected 874 genomic regions over- or under- represented ( $8.2 \%$ of the spots after normalization). However, these differences will not significantly alter genomics regions with high expression ratios $\left(-1 \leq \log _{2} \leq 1\right)$. Therefore, this amplification method (Moreno-Paz and Parro 2006) was validated for further transcriptional analyses.
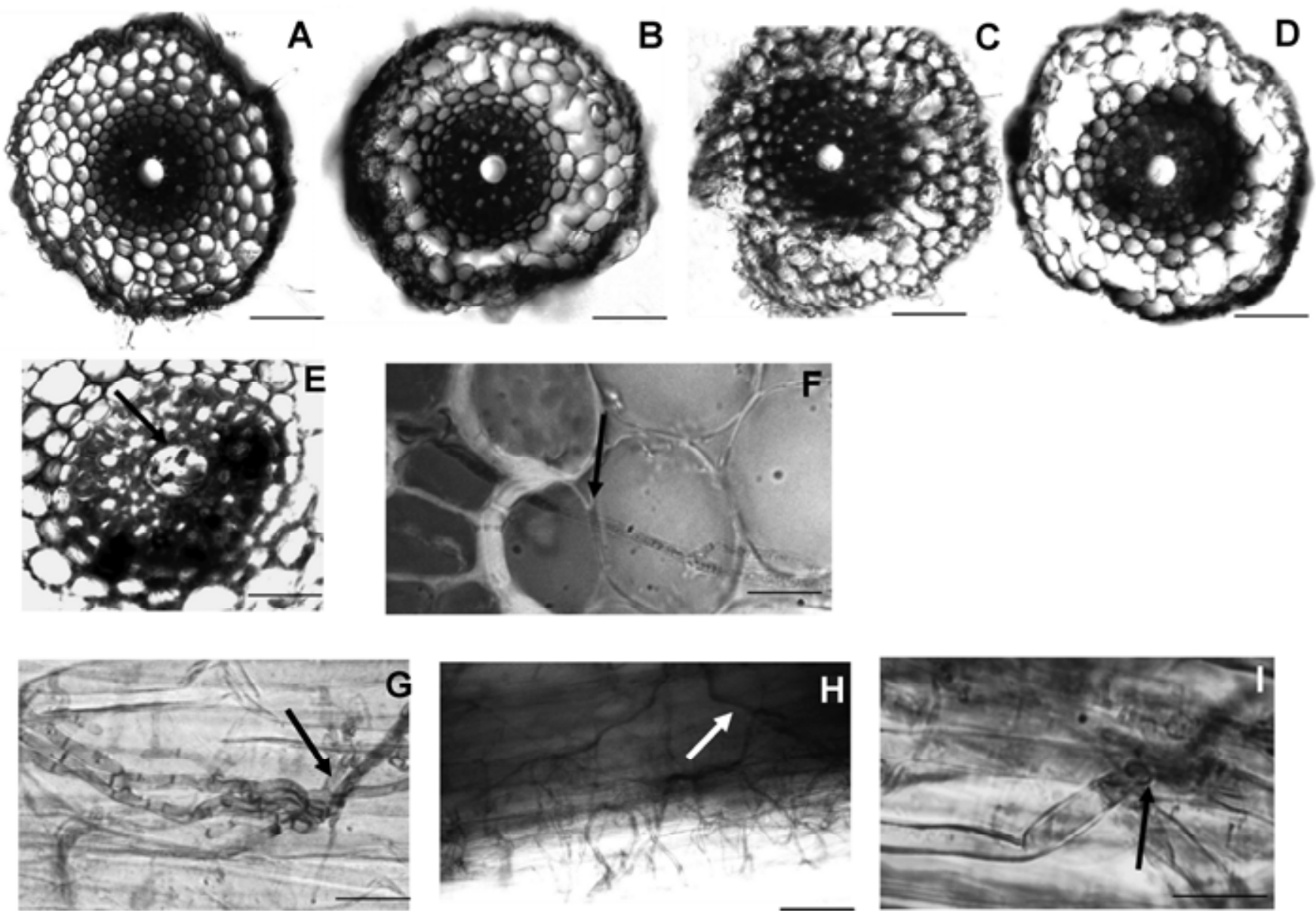

Fig. 3. Colonization stages of wheat roots by Gaeumannomyces graminis var. tritici IV-26/00. Roots of 7 day-old seedlings were inoculated with 8 -mm ${ }^{3}$ (2 by 2 by $2 \mathrm{~mm}$ ) agar plugs containing G. graminis var. tritici IV-26/00 mycelium. Colonization of the root surface and tissues was observed with light microscopy at $\mathbf{B}$ and $\mathbf{G}$, day $9 ; \mathbf{F}$ and $\mathbf{H}$, day 11; C, day 12; and A, D, E, and I, day 14. A, Cross-section of healthy wheat root. B, Cross-section of a wheat root onesided attack by G. graminis var. tritici; the left part of the cortex was filled with mycelium whereas the right part is unaffected. F, Penetration of one hypha (arrow) was visible at junction between two cortical cells. C, Hyphae proliferated within root cortical cells, filling most of the intracellular space and progressed through the endodermis and reached the stele. $\mathbf{D}$ and $\mathbf{E}$, Hyphae colonized xylem tubes and the root cortical tissues were destroyed. Melanized runner hyphae (arrow) grew along the root surface $\mathbf{G}$, before and $\mathbf{H}$, after onset of necrosis. I, Infection hyphae are constricted (arrow) when passing through the cell walls. Bars $=100 \mu \mathrm{m}(\mathrm{A}, \mathrm{B}, \mathrm{C}, \mathrm{D}$, and H); $50 \mu \mathrm{m}(\mathrm{E}) ; 25 \mu \mathrm{m}(\mathrm{F}$ and $\mathrm{G}) ;$ and $10 \mu \mathrm{M}(\mathrm{I})$. 
According to the $F$ test $(P<0.01)$, in total, 3,077 differentially expressed genes were detected in pairwise comparisons of the following growth conditions: $\mathrm{E}$ versus $\mathrm{H}, \mathrm{N}$ versus $\mathrm{H}$, and $\mathrm{N}$ versus $\mathrm{E}$ (Fig. 6). Most differentially expressed genomics regions $(n=3,004)$ were observed in $\mathrm{N}$ versus $\mathrm{H}$, whereas 822 and 698 genomics regions were differentially regulated in $\mathrm{E}$ versus $\mathrm{H}$ and $\mathrm{N}$ versus $\mathrm{E}$, respectively. In total, 1,719, 31, and 38 differentially expressed genomic regions were exclusively found in $N$ versus $H$, E versus $H$, and $N$ versus $E$, respectively. Because of the loop design, we expected that expressed genomic regions would be distributed in two pairwise comparisons. How-
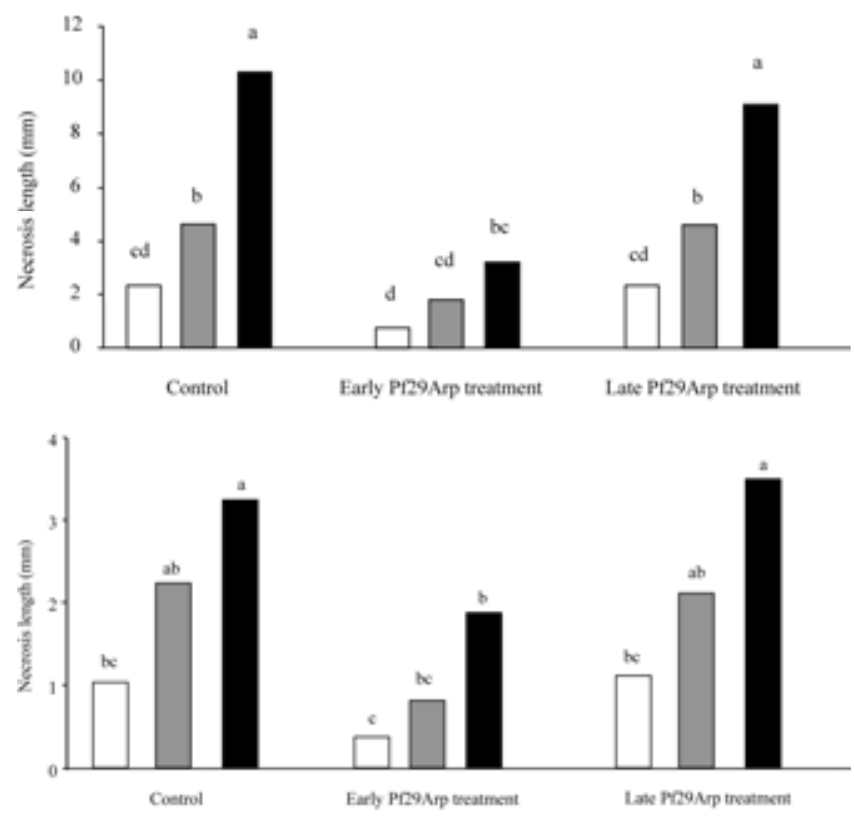

Fig. 4. Effect of Pseudomonas fluorescens Pf29Arp on take-all severity. Wheat seedlings grown in water agar were inoculated with Gaeumannomyces graminis var. tritici IV-26/00. Seedlings were treated with $P$. fluorescens Pf 29Arp at day 9 (before onset of necrosis) or at day 12 (after onset of necrosis). The length of necrosis was calculated from 23 roots at days 11 (white bars), 12 (gray bars), and 14 (black bars). Differences between treatments were analyzed by analysis of variance and were significant at $P=0.05$ ever, the majority of genes exclusively found in one comparison had small fold-change (means: -0.31 and 0.34 ) explaining while they were not found in other comparison.

On the $789(627 \pm 162)$ genomics regions shared between $\mathrm{N}$ versus $\mathrm{H}$ and $\mathrm{E}$ versus $\mathrm{H}$ which were specific to bacterial transcriptome response to the fungal presence on roots, 774 shared the same expression pattern (data not shown), with a slight increase in expression ratio for $\mathrm{N}$ versus $\mathrm{H}$ compared with $\mathrm{E}$ versus $H$ (either up- or downregulated), which was significant for 160 genes present in the intersection of the three comparisons. The $658(162 \pm 496)$ differentially expressed genomics regions shared only between $\mathrm{N}$ versus $\mathrm{E}$ and $\mathrm{N}$ versus $\mathrm{H}$ were specific to bacterial transcriptome response to lesions on roots with 650 genes similarly regulated. Among these 650 genes, a significant increase in expression ratio of 159 genes was found for $\mathrm{N}$ versus $\mathrm{H}$ compared with $\mathrm{N}$ versus $\mathrm{E}$. Finally, 164 (162 \pm 2) genomics regions were specifically shared between $E$ versus

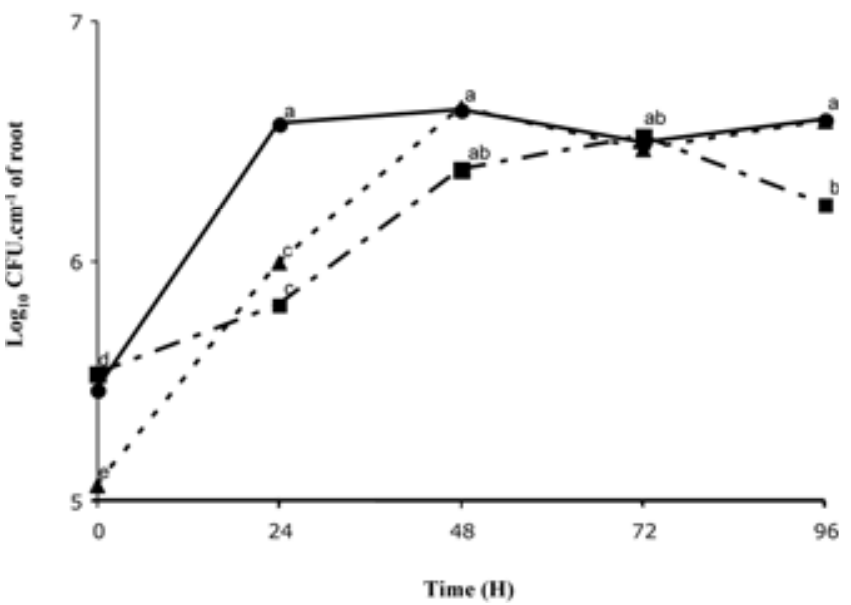

Fig. 5. Pseudomonas fluorescens Pf29Arp population density on the wheat roots in the in vitro confrontation assay. Bacterial density on roots alone $(\mathbf{)})$, on roots early colonized with Gaeumannomyces graminis var. tritici IV-26/00 (ם), or on necrotic roots $(\boldsymbol{\Delta})$ was monitored by dilution plating. Results were expressed in CFU per centimeter of roots as means of three biological replicates each containing two technical replicates. Differences between treatments were analyzed by analysis of variance and were significant at $P=0.05$.
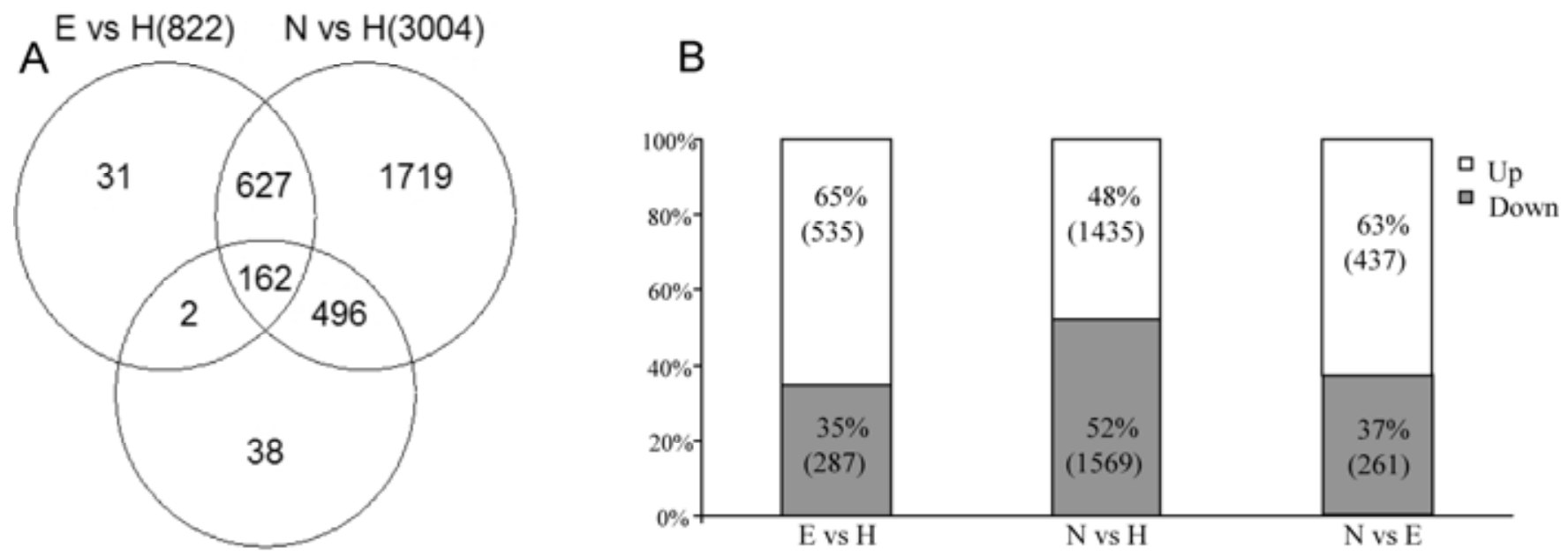

$N$ vs $E(698)$

Fig. 6. Pf 29Arp differentially expressed genomic regions during tripartite interactions. A, Venn diagram showing the number of differentially expressed genomic regions during specific interaction with Pf29Arp. Three ellipses represented different comparative contrasts: early G. graminis var. tritici-colonized roots $(\mathrm{E})$ versus healthy roots $(\mathrm{H})$, necrotic roots $(\mathrm{N})$ versus $\mathrm{H}$, and $\mathrm{N}$ versus E. The overlapped sectors show the number of genes expressed jointly among various phases. B, Genomic regions differentially expressed during Pf29Arp specific interaction were separated into two groups according to whether they were significantly $(P \leq 0.01)$ upregulated (white bars) or downregulated (gray bars). 
$\mathrm{H}$ and $\mathrm{N}$ versus $\mathrm{E}$, with 7 genes similarly regulated. This last intersection corresponded to genes differentially regulated on early G. graminis var. tritici-colonized roots.

\section{Selection and identification \\ of differentially expressed clones.}

In total, 114 genomic regions were selected according to their significant fold change in gene expression $\left(\log _{2}\right.$ transcript ratio $\leq-1$ and $\geq 1$ ) and then sequenced. DNA sequences were compared with databases using the BLASTX algorithm.
Among these 114 genomics regions, 66 were represented once, 16 twice, 4 three times, and 1 four times. Redundant genomic regions were similarly regulated, confirming the reliability of the hybridization data. In total, 169 open reading frames (ORF) were identified, indicating that $33 \%$ of the genomic regions contained more than one transcript. Two genomic regions shared no significant homology $\left(E\right.$ value $\left.>1.10^{-4}\right)$ with sequences in database (clone number $9 \mathrm{~N} 22$ and 38C24).

Genes were grouped according to their expression pattern in the three conditions (Table 1). Genomic regions which con-

Table 1. Genes of Pseudomonas fluorescens Pf 29Arp with altered expression between healthy, early colonized, and necrotic roots ${ }^{\mathrm{a}}$

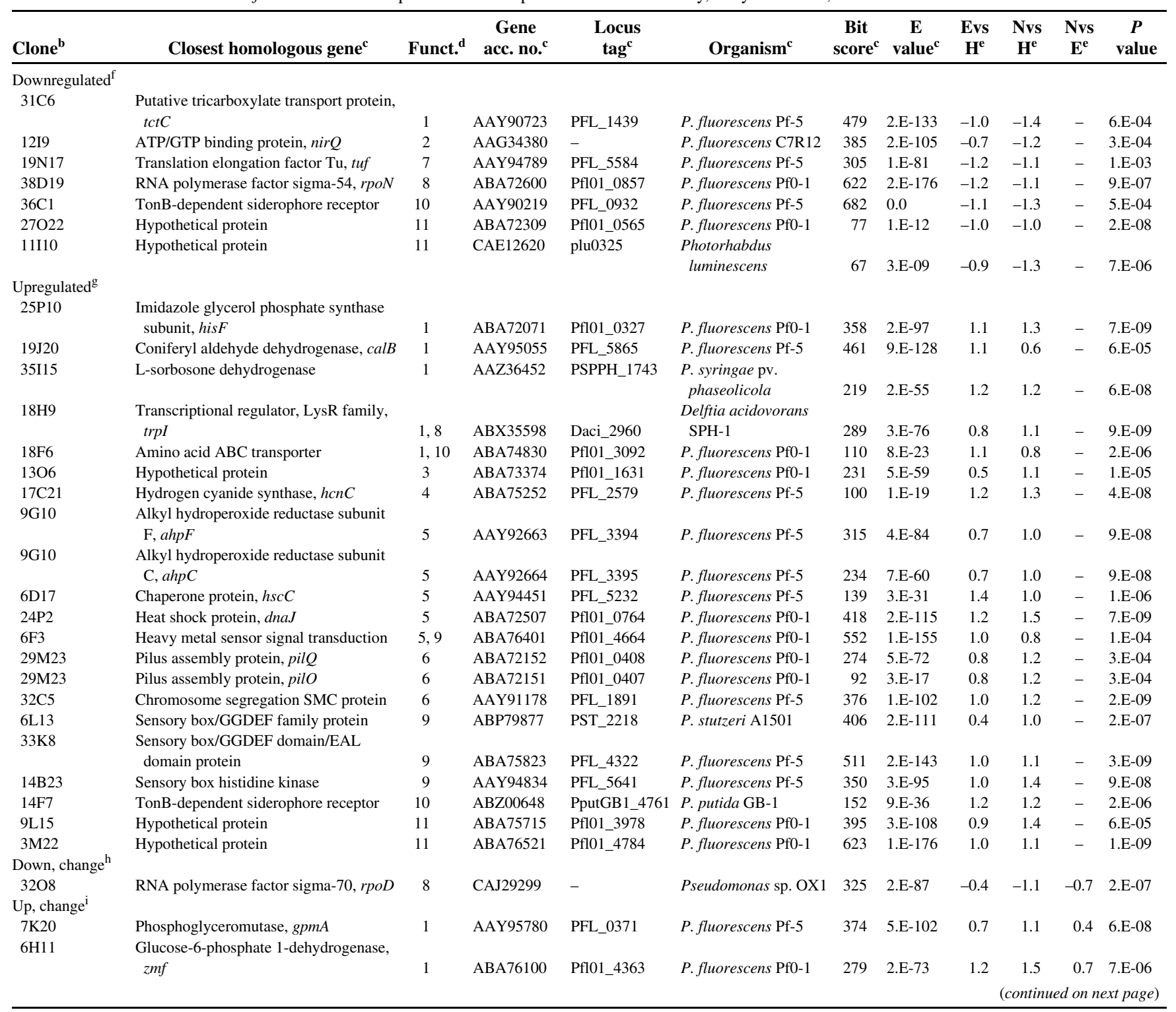

${ }^{a}$ Genomic regions containing more than one open reading frame (ORF) were discarded for subsequent analysis expect for genes which expression was validated by quantitative reverse-transcription polymerase chain reaction (hcnC, rraA, PputGB1_4761), ORF organized in operon (pilOQ, PFL_2600-Pf101_3324, dinF-Pf101_0629, potHA, Pf101_01060107), and one pair with the same biological function $(a h p F, a h p C)$

$\mathrm{b}$ Clone number referred to the genomic library number.

${ }^{\mathrm{c}}$ Best BlastX hit.

${ }^{\mathrm{d}}$ Genes were classed according to their expression ratios in the three conditions: healthy roots (H), early G. graminis var. tritici-colonized roots (E), and necrotic roots (N). For each condition, genes were classed by functional categories: 1, carbon-nitrogen metabolism; 2, denitrification pathway; 3 , nucleotide-nucleic acid metabolism; 4, secondary metabolism; 5, stress response; 6 , motility and cell biogenesis; 7, translation; 8, transcriptional regulator; 9 , signaling; and 10, transport.

e Expression ratio ( $\log _{2}$ fold change $-1<$ or $>1$ ) of the three contrasts (E versus $\mathrm{H}, \mathrm{N}$ versus $\mathrm{H}$, and $\mathrm{N}$ versus E) is given for genes statistically differentially regulated according to the $F$ test $(P<0.01) ;-=$ genes nonstatistically differentially regulated.

${ }^{\mathrm{f}}$ Genes downregulated on roots infected with $G$. graminis var. tritici.

${ }^{\mathrm{g}}$ Genes upregulated on roots infected with G. graminis var. tritici.

${ }^{\text {h }}$ Genes downregulated on roots infected with G. graminis var. tritici with highest fold-change on necrotic roots.

i Genes upregulated on roots infected with G. graminis var. tritici with highest fold-change on necrotic roots.

${ }^{j}$ Gene upregulated on early G. graminis var. tritici colonized roots.

${ }^{\mathrm{k}}$ Genes downregulated on necrotic roots. 
tained more than one ORF were discarded for subsequent analysis (Supplementary Table S1) except for genes for which expression was validated by quantitative reverse-transcriptase (Q-RT)PCR (hcnC, rraA, PputGB1_4761), ORF organized in operon (pilO/pilQ, PFL_2600/Pf101_3324, dinF/Pfl01_0629, potH/ potA, Pfl01_0106/Pfl01_0107), and one pair with the same biological function $(a h p F, a h p C)$. For most groups, the presence of the fungal pathogen on roots clearly altered Pf29Arp transcript abundance, with a most pronounced effect for necrotic roots.

Many bacterial genes with predicted functions related to nutrient acquisition, including amino acid (e.g., thrC encoding a threonine synthase), carbohydrate (e.g., gpmA encoding a phosphoglyceromutase) and tricarboxylate (e.g., PFL_2499 encoding a citrate transporter) transport and metabolism, were differentially expressed on $\mathrm{E}$ and $\mathrm{N}$ roots compared with $\mathrm{H}$ roots. In parallel, global regulators of carbon and nitrogen sources, such as $g b d R$ encoding a transcriptional regulator required for glycine betaine catabolism and $c b r B$ encoding the regulator of the two-component system $\mathrm{CbrAB}$ involved in several pathway regulation in response to $\mathrm{C}: \mathrm{N}$ ratio, were progressively induced during the development of G. graminis var. tritici pathogenesis $(\mathrm{H}<\mathrm{E}<\mathrm{N})$. A gene involved in iron

Table 1. continued from preceding page

\begin{tabular}{|c|c|c|c|c|c|c|c|c|c|c|c|}
\hline Clone $^{b}$ & Closest homologous gene ${ }^{c}$ & Funct. $^{d}$ & $\begin{array}{c}\text { Gene } \\
\text { acc. no. }\end{array}$ & $\begin{array}{l}\text { Locus } \\
\operatorname{tag}^{c}\end{array}$ & Organism $^{c}$ & $\begin{array}{c}\text { Bit } \\
\text { score }^{c}\end{array}$ & $\underset{\text { value }^{c}}{\mathbf{E}}$ & $\begin{array}{c}\text { Evs } \\
\mathbf{H}^{\mathbf{e}}\end{array}$ & $\begin{array}{c}\text { Nvs } \\
\mathbf{H}^{\mathrm{e}}\end{array}$ & $\underset{\mathbf{E}^{\mathrm{e}}}{\mathrm{Nvs}}$ & $\begin{array}{c}P \\
\text { value }\end{array}$ \\
\hline \multicolumn{12}{|c|}{ Up, change ${ }^{\mathrm{i}}$ (continued) } \\
\hline 19P5 & DNA-binding response regulator, $c b r B$ & 1,8 & AAY35889 & Psyr_0831 & $\begin{array}{l}\text { P. syringae pv. syringae } \\
\text { B728a }\end{array}$ & 321 & 4.E-86 & 1.0 & 1.3 & 0.6 & 6.E-08 \\
\hline $17 \mathrm{P} 20$ & $\begin{array}{l}\text { Transcriptional activator, AraC family, } \\
\text { ftrA }\end{array}$ & 1,8 & ABA73805 & Pf101_2062 & P. fluorescens $\mathrm{Pf0}-1$ & 328 & 5.E-88 & 0.5 & 1.1 & 0.7 & 8.E-09 \\
\hline $36 \mathrm{P} 5$ & $\begin{array}{l}\text { Transcriptional Regulator, AraC family, } \\
g b d R\end{array}$ & 1,8 & ABA76973 & Pfl01_5236 & P. fluorescens $\mathrm{PfO}-1$ & 390 & 6.E-107 & 0.8 & 1.2 & 0.4 & 2.E-10 \\
\hline $10 \mathrm{M} 1$ & DNA primase, $d n a G$ & 3 & ABA76885 & Pf101_5148 & P. fluorescens $\mathrm{PfO}-1$ & 392 & 2.E-107 & 0.7 & 1.4 & 0.7 & 5.E-06 \\
\hline 19D24 & $\begin{array}{l}\text { Ribonuclease activity regulator protein, } \\
\operatorname{rraA}\end{array}$ & 3 & AAY91159 & PFL_1871 & P. fluorescens Pf-5 & 113 & 2.E-23 & 0.9 & 1.3 & 0.3 & 5.E-10 \\
\hline $35 \mathrm{~K} 6$ & $\begin{array}{l}\text { DNA polymerase III subunits gamma } \\
\text { and tau, } d n a X\end{array}$ & 3 & ABA73548 & Pf101_1805 & P. fluorescens $\mathrm{Pf0}-1$ & 617 & 4.E-175 & 0.9 & 1.1 & 0.4 & 5.E-10 \\
\hline $36 \mathrm{O} 21$ & $\begin{array}{l}\text { Ribose-phosphate pyrophosphokinase, } \\
\text { prs }\end{array}$ & 3 & AAY96268 & PFL_5165 & P. fluorescens Pf-5 & 310 & 1.E-82 & 1.0 & 1.3 & 0.5 & 3.E-11 \\
\hline $33 \mathrm{G} 15$ & RNA 3'-terminal-phosphate cyclase, $r t c A$ & 3 & ABP83956 & Pmen_1191 & P. mendocina ymp & 120 & 4.E-52 & 1.4 & 1.9 & 0.7 & 3.E-09 \\
\hline $35 \mathrm{G} 3$ & Amino acid adenylation & 4 & ABA73590 & Pf101_1847 & P. fluorescens $\mathrm{PfO}-1$ & 293 & 1.E-77 & 0.8 & 1.1 & 0.4 & 9.E-10 \\
\hline $13 \mathrm{O} 4$ & Putative catalase & 5 & AAY93210 & PFL_3946 & P. fluorescens Pf-5 & 383 & 8.E-105 & 0.4 & 1.2 & 0.6 & 1.E-07 \\
\hline $17 \mathrm{~L} 21$ & Cytochrome $\mathrm{c}$ oxidase, subunit II, $\operatorname{cox} B$ & 5 & ABA71823 & Pf101_0079 & P. fluorescens $\mathrm{PfO}-1$ & 504 & 3.E-141 & 0.6 & 1.1 & 0.6 & 4.E-09 \\
\hline $20 \mathrm{C} 8$ & DnaJ domain protein, putative & 5 & AAY94452 & PFL_5233 & P. fluorescens $\mathrm{Pf}-5$ & 80 & 2.E-13 & 1.0 & 1.3 & 0.6 & 6.E-10 \\
\hline $31 \mathrm{G} 7$ & Multidrug extrusion superfamily, $\operatorname{din} F$ & 5,10 & AAY 96087 & PFL_0680 & P. fluorescens $\mathrm{Pf}-5$ & 141 & 6.E-32 & 0.9 & 1.3 & 0.5 & 3.E-11 \\
\hline $10 \mathrm{~J} 1$ & Glycosyl transferase, family 2 & 6 & ABJ81477 & Acid_0467 & $\begin{array}{l}\text { Solibacter usitatus } \\
\text { Ellin6076 }\end{array}$ & 113 & 2.E-23 & 0.5 & 1.0 & 0.4 & 7.E-07 \\
\hline $36 \mathrm{~A} 21$ & Periplasmic beta-glucosidase, $b g l X$ & 6 & AAY 90636 & PFL_1351 & P. fluorescens $\mathrm{Pf}-5$ & 788 & 0.0 & 0.9 & 1.2 & 0.5 & $6 . \mathrm{E}-10$ \\
\hline 20P19 & S-adenosylmethionine:tRNA, queA & 7 & АAT96042 & - & P. viridiflava & 205 & 5.E-51 & 0.8 & 1.5 & 0.9 & 7.E-11 \\
\hline $3 \mathrm{~A} 22$ & Transcriptional regulator LuxR family & 8 & ABA74200 & Pf101_2459 & P. fluorescens $\mathrm{PfO}-1$ & 163 & 1.E-38 & 0.9 & 1.2 & 0.6 & 6.E-08 \\
\hline $10 \mathrm{~N} 19$ & Transcriptional Regulator, AraC family & 8 & ABA74612 & Pf101_2871 & P. fluorescens Pf0-1 & 473 & 7.E-132 & 1.4 & 1.8 & 1.0 & 3.E-08 \\
\hline $37 I 4$ & $\begin{array}{l}\text { Putative diguanylate } \\
\text { cyclase/phosphodiesterase }\end{array}$ & 9 & ABA76992 & Pf101_5255 & P. fluorescens $\mathrm{Pf0}-1$ & 516 & 1.E-144 & 0.7 & 1.0 & 0.4 & $6 . \mathrm{E}-10$ \\
\hline $20 \mathrm{~K} 1$ & $\begin{array}{l}\text { Hemolysin activator protein, HlyB } \\
\text { family }\end{array}$ & 10 & AAY90834 & PFL_1551 & P. fluorescens Pf-5 & 545 & 2.E-153 & 0.6 & 1.0 & 0.4 & 9.E-10 \\
\hline $36 \mathrm{O} 23$ & Rhs element Vgr protein & 10 & ABA75416 & Pf101_3678 & P. fluorescens $\mathrm{Pf0}-1$ & 237 & 8.E-61 & 0.7 & 1.1 & 0.4 & 9.E-11 \\
\hline $19 \mathrm{C} 13$ & $\begin{array}{l}\text { Binding-protein-dependent transport } \\
\text { systems, pot } H\end{array}$ & 10 & ABA72789 & Pf101_1046 & P. fluorescens Pf0-1 & 179 & 5.E-42 & 1.0 & 1.6 & 0.6 & 2.E-08 \\
\hline $19 \mathrm{C} 13$ & $\begin{array}{l}\text { Spermidine/putrescine } \mathrm{ABC} \text { transporter, } \\
\text { potA }\end{array}$ & 10 & ABA72790 & Pf101_1047 & P. fluorescens Pf0-1 & 297 & 7.E-79 & 1.0 & 1.6 & 0.6 & 2.E-08 \\
\hline $37 \mathrm{~N} 1$ & $\begin{array}{l}\text { Outer membrane ferric siderophore } \\
\text { receptor, putative }\end{array}$ & 10 & AAN68936 & PP3330 & P. putida $\mathrm{KT} 2440$ & 268 & 3.E-70 & 2.1 & 2.5 & 1.1 & 3.E-11 \\
\hline 9011 & Hypothetical protein & 11 & ABA76031 & Pf101_4294 & P. fluorescens $\mathrm{Pf0}-1$ & 145 & 4.E-33 & 0.6 & 1.1 & 0.5 & 1.E-07 \\
\hline $31 \mathrm{E} 24$ & Hypothetical protein & 11 & AAO58016 & PSPTO_4570 & $\begin{array}{l}\text { P. syringae pv. tomato } \\
\text { DC } 3000\end{array}$ & 115 & 5.E-24 & 0.7 & 1.4 & 0.6 & 2.E-09 \\
\hline $34 \mathrm{E} 21$ & Hypothetical protein & 11 & AAY91873 & PFL_2600 & P. fluorescens Pf-5 & 102 & 3.E-20 & 0.8 & 1.1 & 0.6 & 1.E-07 \\
\hline $34 \mathrm{E} 21$ & Hypothetical protein & 11 & ABA75061 & Pf101_3324 & P. fluorescens $\mathrm{PfO}-1$ & 117 & 1.E-24 & 0.8 & 1.1 & 0.6 & 1.E-07 \\
\hline $31 \mathrm{G} 7$ & Hypothetical protein & 11 & ABA72373 & Pf101_0629 & P. fluorescens $\mathrm{Pf0}-1$ & 405 & 4.E-51 & 0.9 & 1.3 & 0.5 & 3.E-11 \\
\hline $15 \mathrm{~A} 1$ & Hypothetical protein & 11 & ABM33693 & Aave_3129 & $\begin{array}{l}\text { Acidovorax avenae } \\
\text { AAC } 00-1\end{array}$ & 106 & 3.E-21 & 0.9 & 1.4 & 0.5 & 9.E-09 \\
\hline $5 B 6$ & Hypothetical protein & 11 & ABA71850 & Pf101_0106 & P. fluorescens Pf0-1 & 469 & 1.E-130 & 1.8 & 2.4 & 1.2 & 9.E-10 \\
\hline $5 \mathrm{~B} 6$ & Hypothetical protein & 11 & ABA71851 & Pf101_0107 & P. fluorescens Pf0-1 & 87 & 2.E-15 & 1.8 & 2.4 & 1.2 & 9.E-10 \\
\hline $5 \mathrm{~K} 9$ & Hypothetical protein & 11 & ABA71785 & Pf101_0041 & P. fluorescens $\mathrm{PfO}-1$ & 442 & 2.E-122 & 2.1 & 0.5 & 0.3 & 2.E-07 \\
\hline \multicolumn{12}{|l|}{ Up, early ${ }^{j}$} \\
\hline $3 \mathrm{P} 9$ & Toluene tolerance protein, putative, $\operatorname{ttg} 8$ & 5 & AAY35605 & Psyr_0535 & $\begin{array}{l}\text { P. syringae pv. syringae } \\
\text { B728a }\end{array}$ & 276 & 2.E-72 & 1.6 & -0.3 & - & 1.E-03 \\
\hline \multicolumn{12}{|c|}{ Down, necrotic ${ }^{k}$} \\
\hline $25 \mathrm{~K} 13$ & Aldose 1-epimerase & 1 & ABA76102 & Pf101_4365 & P. fluorescens $\mathrm{Pf0}-1$ & 536 & 1.E-150 & - & -1.1 & -1.0 & 1.E-06 \\
\hline 33B13 & Major facilitator superfamily MFS_1 & 5,10 & AAY93662 & PFL_4411 & P. fluorescens $\mathrm{Pf}-5$ & 343 & 1.E-92 & - & -1.0 & -1.1 & 1.E-06 \\
\hline $8 \mathrm{P} 10$ & Hypothetical protein & 11 & ABA76950 & Pf101_5213 & P. fluorescens $\mathrm{Pf0}-1$ & 243 & 1.E-62 & - & -1.3 & -0.8 & 5.E-06 \\
\hline $12 \mathrm{~B} 17$ & Hypothetical protein & 11 & ABA77411 & Pf101_5675 & P. fluorescens $\mathrm{PfO}-1$ & 396 & 1.E-108 & - & -1.2 & -1.1 & 6.E-09 \\
\hline $8 \mathrm{I} 2$ & Threonine synthase, $\operatorname{thr} C$ & 1 & AAY90391 & PFL_1104 & P. fluorescens Pf-5 & 291 & 7.E-77 & - & -1.0 & - & 5.E-04 \\
\hline 34011 & $\begin{array}{l}\text { Phosphate starvation-inducible protein, } \\
\text { psiF }\end{array}$ & 9 & AAY96027 & PFL_0620 & P. fluorescens $\mathrm{Pf}-5$ & 151 & 6.E-35 & - & -1.3 & - & 1.E-03 \\
\hline
\end{tabular}


acquisition (PputGB1_4761 encoding a TonB-dependent siderophore receptor) was upregulated on $\mathrm{E}$ and $\mathrm{N}$, whereas a gene of the denitrification process (nir $Q$ encoding a putative ATP-binding protein) was positively regulated on $\mathrm{H}$ roots.

Another relevant result was that bacterial genes related to stress (e.g., PFL_3946 encoding a putative catalase) and detoxification processes (e.g., $\operatorname{din} F$ and ttg8 encoding DNAdamage-inducible protein $\mathrm{F}$ and a putative toluene tolerance protein, respectively) were induced in $\mathrm{E}$ and $\mathrm{N}$ compared with H. A number of chemotaxis (e.g., PSPA7_2644 encoding a putative chemotaxis transducer) and cell biogenesis-related genes (e.g., $b g l X$ encoding a periplasmic beta-glucosidase) were also upregulated in $\mathrm{E}$ and $\mathrm{N}$. The same pattern of regulation was observed for genes encoding secreted proteins (e.g., PFL_1551 and Pfl01_3678 encoding a hemolysin activator protein belonging to the T5SS TpsB family and a putative type VI secretion system [T6SS] effector, respectively) and in the modulation of RNA abundance (e.g., rraA encoding a ribonuclease activity regulator protein). Finally, the gene hcnC encoding a putative amino-acid oxidase involved in hydrogen cyanide (HCN) synthesis was upregulated by the fungal presence.

\section{Validation of selected gene expression.}

To validate the results obtained with the Pf29Arp DNA microarray, Q-RT-PCR was performed on 11 genes differentially regulated and which were representative of each gene class (except for class 7, 8, 9, and 11). This included the following genes: thrC, bglX, nirQ, PFL_3946, dinF, Psyr_0535, PputGB1_4761, PFL_1551, rraA, and hcnC (Supplementary Table S2).

The analysis showed that the majority of transcripts (bglX, PFL_3946, PFL_1551, PputGB1_4761, rraA, and hcnC) exhibited the same expression ratios as observed with the microarrays (Table 2). However, some genes that exhibited small fold changes on microarray in a specific condition (e.g., dinF, Pfl01_3678, and Psyr_0535) were apparently not differentially expressed, and genes not regulated in the microarray at a specific stage (e.g., thrC, $\operatorname{din} F$, and $\operatorname{nir} Q$ ) were differentially expressed as mean by Q-RT-PCR.

\section{DISCUSSION}

In this work, we have tracked alterations of bacterial transcripts during the establishment of Pf 29Arp populations at the surface of wheat roots infected with G. graminis var. tritici. First, pathogenesis and bacterial colonization were monitored in tripartite gnotobiotic experiments and compared with bipartite experiments. In the absence of bacterial inoculation, $G$. graminis var. tritici mycelium first grew mainly ectotrophically on roots (stage E); then, the mycelium reached the stele and the necrosis largely extended (stage N). Only inoculation of Pf29Arp on early $G$. graminis var. tritici-colonized roots led to a drop in incidence and severity of take-all disease after 48 $\mathrm{h}$ of interaction compared with the control without bacterial inoculation. This effect could be explained by different direct and indirect mechanisms such as competition for niches and nutrient between Pf29Arp and G. graminis var. tritici outside the plant, antibiosis or fungistasis toward G. graminis var. tritici, and induced plant resistance (Haas and Defago 2005). Such niche competition was already reported between $F$. oxysporum and biocontrol pseudomonads on tomato roots at the intercellular junctions (Bolwerk et al. 2003). In contrast, when necrosis or deep root colonization was first developed (N), no biocontrol activity could affect the protected mycelium inside roots.

Although the same population density of Pf29Arp was reached at $48 \mathrm{~h}$ in each of the three treatments $(\mathrm{H}, \mathrm{E}$, and $\mathrm{N})$, differences in early colonization patterns were observed. On healthy roots, population density reached $5 \times 10^{6} \mathrm{CFU} \mathrm{cm} \mathrm{cm}^{-1}$ of roots at $24 \mathrm{~h}$ and was maintained up to $96 \mathrm{~h}$. Unexpectedly, after the onset of necrosis, Pf29Arp population density dramatically and rapidly dropped. Stressful environment conditions, such as accumulation of phenolics compounds on necrotic roots (Rengel et al. 1994), could explain this rapid bacterial cell death. Necrosis could also have changed root surface physical properties and avoided bacterial adhesion to root tissues. On early $G$. graminis var. tritici-colonized roots, a four times less increase in bacterial multiplication rate was observed, which could be explained by competition for nutrients and space between Pf29Arp and G. graminis var. tritici.

Here, bacterial and fungal fitness were measured as Pf29Arp growth rate and take-all severity and incidence, respectively. On early G. graminis var. tritici-colonized roots, the interspecific relationship was negative for both microbial partners compared with their respective growth and infectivity on roots without the other partner. Therefore, competitive interactions between Pf29Arp and G. graminis var. tritici have occurred. On necrotic roots, the interaction was neutralistic because neither negative nor beneficial effects were measured for the fungus and Pf29Arp. Usually, biocontrol strains are described as antagonistic or parasitic toward fungi missing mutualistic and neutral rhizobacteria occurrence in the same pathosystem as described by Sarniguet and associates (1992). Because commensal and

Table 2. Relative expression levels of Pseudomonas fluorescens Pf 29Arp genes by the microarray approach versus the quantitative reverse-transcription polymerase chain reaction (Q-RT-PCR) approach ${ }^{\mathrm{a}}$

\begin{tabular}{|c|c|c|c|c|c|c|c|}
\hline \multirow[b]{2}{*}{ Genes } & \multirow[b]{2}{*}{ Putative function of protein } & \multicolumn{2}{|c|}{ E versus $\mathbf{H}$} & \multicolumn{2}{|c|}{$\mathbf{N}$ versus $\mathbf{H}$} & \multicolumn{2}{|c|}{$\mathbf{N}$ versus $\mathbf{E}$} \\
\hline & & Microarray & Q-RT-PCR $^{\mathbf{b}}$ & Microarray & Q-RT-PCR ${ }^{b}$ & Microarray & Q-RT-PCR $^{\mathbf{b}}$ \\
\hline thrC & Threonine synthase & - & -0.85 & -0.99 & -0.71 & - & 0.12 \\
\hline$b g l X$ & Periplasmic beta-glucosidase & 0.94 & 0.74 & 1.24 & 1.70 & 0.49 & 1.04 \\
\hline $\operatorname{nir} Q$ & ATP/GTP binding protein, NirQ & -0.71 & -1.33 & -0.60 & -0.38 & - & 0.69 \\
\hline PFL_3946 & Catalase, putative & 0.44 & 0.24 & 1.18 & 0.89 & 0.57 & 0.66 \\
\hline $\operatorname{din} F$ & DNA-damage-inducible protein $\mathrm{F}$ & 0.94 & 0.08 & 1.33 & 0.72 & 0.51 & 0.91 \\
\hline Psyr_0535 & Toluene tolerance protein putative & 1.58 & 0.84 & -0.30 & 0.49 & - & -0.58 \\
\hline PputGB1_4761 & TonB-dependent siderophore receptor & 1.20 & 0.51 & 1.18 & 0.83 & - & 0.36 \\
\hline Pf101_3678 & Rhs element Vgr protein & 0.72 & 0.17 & 1.11 & 1.20 & 0.42 & 1.00 \\
\hline PFL_1551 & Hemolysin activator protein, HlyB family & 0.61 & 0.75 & 1.02 & 0.94 & 0.41 & 0.07 \\
\hline $\operatorname{rraA}$ & Ribonuclease activity regulator protein & 0.86 & 0.44 & 1.30 & 1.08 & 0.31 & 0.60 \\
\hline$h c n C$ & Hydrogen cyanide synthase & 1.21 & 1.43 & 1.28 & 2.10 & - & 0.42 \\
\hline
\end{tabular}

${ }^{a}$ Data came from measurements performed by real-time PCR on Pf 29Arp cDNAs obtained from healthy (H), G. graminis var. tritici early-colonized (E), and necrotic roots $(\mathrm{N})$. Three pairwise comparisons (E versus $\mathrm{H}, \mathrm{N}$ versus $\mathrm{H}$, and $\mathrm{N}$ versus $\mathrm{E}$ ) were made. The expression level of each gene of interest was calculated by dividing the quantities for each sample by the appropriate geNorm normalization factor.

${ }^{\mathrm{b}}$ Each value is the mean of three biological replicates and two technical replicates. Data in bold highlight significant changes in expression level (interval confidence, $P=0.05) ;-=$ genes nonstatistically regulated on microarray. 
mutualistic interactions were previously observed during in vitro co-cultures of Pf29Arp with G. graminis var. tritici (Barret et al. 2009) and with the ectomycorrhizal fungus Laccaria bicolor S238N (Deveau et al. 2007), respectively, our results highlight that the same biocontrol rhizobacteria can differentially interact with a filamentous fungus along its life cycle.

Roots infected with $G$. graminis var. tritici strongly modified Pf29Arp transcriptome with 100- to 400-fold more genomic regions differentially expressed compared with $G$. graminis var. tritici alone (Barret et al. 2009). In total, 27 common genomic regions were significantly regulated in both the $G$. graminis var. tritici hyphosphere and roots infected with $G$. graminis var. tritici. However, only one gene (PputGB1_4761) had a twofold change-expression ratio. The low overlap between these outcomes could be explained by differences in experimental conditions. Indeed, direct influence of $G$. graminis var. tritici on Pf 29Arp transcript abundance was studied before cell-to-cell contact up to contact on a complete media (Barret et al. 2009).

Two main expression patterns of sequenced clones were identified. The first pattern fitted with genes regulated by the fungal presence on roots compared with healthy roots. For example, nir $Q$, which encodes a putative ATP-binding protein, was downregulated during the two $G$. graminis var. tritici infection stages when compared with healthy roots. NirQ is involved in regulation of the nitric oxide (NO) reduction pathway in P. stutzeri (Jungst and Zumft 1992). NO is generated and reduced by bacterial denitrification, a process in which bacteria utilize oxidized nitrogen as electron acceptors when oxygen concentration is limited. Denitrification may constitute a significant advantage for root colonization because denitrifying bacteria predominantly occur near or inside roots (Philippot et al. 1995; Ghiglione et al. 2000). Here, we showed that a homologous genes was upregulated on healthy roots and downregulated in the presence of G. graminis var. tritici $(\mathrm{E}$ and $\mathrm{N}$ ), meaning that understanding the entire process of root colonization by biocontrol bacteria must take into account the presence of pathogens.

The gene $h c n C$, belonging to the $h c n A B C$ operon encoding cyanide synthase (Laville et al. 1998), was also upregulated on $G$. graminis var. tritici infected roots. In P. fluorescens, HCN synthesis accounts for a part of the biocontrol capacity against suppression of Thielaviopsis basicola (Voisard et al. 1989) and G. graminis var. tritici (Sarniguet et al. 1992; Blumer and Haas 2000). Similarly, the presence of Rhizoctonia solani in the bean rhizosphere increases hcnA expression in the biocontrol strain P. fluorescens CHA0 (Jamali et al. 2009). However, HCN synthesis by Pf29Arp was not detected in vitro on glycine medium (data not shown). Because HCN synthesis could be effective only under low oxygen pressure in P. aeruginosa (Cody et al. 2009), production of this metabolite on $G$. graminis var. tritici-colonized roots remains to be assessed.

On roots colonized with $G$. graminis var. tritici, an ORF sharing $82 \%$ identity at the amino acid level with a hemolysin activator protein of $P$. fluorescens Pf-5 (PFL_1551) was identified. This gene belonged to the TpsB transporter family of the twopartner secretion pathway (TPS) (Jacob-Dubuisson et al. 2001). TPS systems are encoded by two genes generically designated tps $A$, encoding the secreted protein and $t p s B$, encoding a dedicated transporter, which are frequently located in an operon (Jacob-Dubuisson et al. 2004). The gene immediately downstream, PFL_1551 in P. fluorescens Pf29Arp, shared 53\% identity at the amino acid level with a filamentous hemagglutinin protein (PFL_1552) of P. fluorescens Pf-5 that is the TpsAsecreted protein. Haemagglutinin facilitates the attachment of bacteria to mammalian (Locht et al. 1993) and vegetal (Rojas et al. 2002) host-cells; therefore, PFL_1551 could also be involved in this trait.

The second expression pattern of Pf 29Arp-sequenced clones contained genes highly regulated on necrotic roots when compared with early-colonized roots. For example, a significant induction for genes involved in $\mathrm{C}$ and $\mathrm{N}$ metabolism was detected between necrotic roots and roots early colonized with G. graminis var. tritici, which could suggest either an increase in nutrient availability due to leakage from damaged root tissues (Curl and Truelove 1986) or a nutrient limitation on this environment. For example, $g b d R$, which encodes the regulator of glycine betaine catabolic genes that is activated by glycine betaine accumulation (Wargo et al. 2008), is induced on necrotic roots. Similarly, induction of $\operatorname{cbr} B$ encoding the regulator of the two-component system $\mathrm{CbrAB}$ which controls the expression of numerous catabolic pathways in response to changing intracellular C:N ratios in Pseudomonas spp. (Nishijyo et al. 2001; Zhang and Rainey 2008) could reflect a shift in nutrient availability.

Bacterial genes with predicted functions related to oxidative stress (gene PFL_3946 encoding a catalase, $a h p F, a h p C$ ) and detoxification process $(\operatorname{din} F)$ were upregulated on $G$. graminis var. tritici-colonized roots with a significant increase in expression ratio on necrotic roots. The progressive induction of bacterial stress-responsive genes during G. graminis var. tritici development was probably linked to continually increasing levels of plant defense mechanisms against this fungus. Indeed, the first step of the defense mechanism in plants involves a rapid accumulation of phenols at the infection site (Nicholson and Hammerschmidt 1992). Following this, phenol oxidation leads to browning of tissues (Hammerschmidt 2005) and the formation of quinones and free radicals that have antimicrobial activities (Appel 1992). In agreements with these observations, Sari and associates (2008) have shown that the amount of phenolic compounds and oxidase enzymes in wheat roots treated with $G$. graminis var. tritici and the biocontrol strain $P$. fluorescens CHA0 increases progressively until 6 days after pathogen inoculation. Although this could explain the upregulation of bacterial genes involved in oxidative stress and detoxification process, we cannot exclude the possibility that compounds produced by the fungus itself could also activate some of these bacterial stressresponsive genes, as already observed in Pf29Arp-G. graminis var. tritici co-cultures (Barret et al. 2009). Even when colonizing healthy roots, Pf29Arp has to develop protection mechanisms because genes encoding glutathione $S$-transferase and multidrug resistance efflux pump were induced at this stage. Clearly, stress adaptation is an important trait for colonization of roots infected or not with $G$. graminis var. tritici.

Among this second expression pattern, some Pf29Arp genes were specifically induced on necrotic roots. For example, $r r a A$ was specifically upregulated on necrotic roots. In Escherichia coli, the protein RraA interacts with RNAse E and inhibits its endoribonuclease action, leading to global change in RNA abundance (Lee et al. 2003). Furthermore, instead of simply acting as general inhibitors of RNAse E, RraA specifically modulates RNA decay and, therefore, affects the intracellular levels of distinct sets of transcript (Gao et al. 2006). No experimental evidence on the role of RraA in Pseudomonas spp. is yet available, but $r a A$ is widely distributed among bacteria and plants (Lee et al. 2003) and possesses the same intrinsic activity in other bacterial species (Yeon et al. 2008; Lee et al. 2009).

Similarly, one ORF, which shares 53\% identity at the amino acid level with an Rhs element Vgr protein of $P$. fluorescens Pf0-1 (Pfl01_3678), was specifically upregulated on necrotic roots. The predicted protein of Pf29Arp belongs to the VgrG protein family of the type VI effector, as suggested by domains analysis by InterProScan. T6SS is defined by a set of structural 
components which may vary in terms of organization and composition between species (Filloux et al. 2008; Pukatzki et al. 2009). In many species, T6SS appears to be a major virulence determinant (Mougous et al. 2006; Pukatzki et al. 2007) whereas, in others, it decreases the infection (Mattinen et al. 2008; Wu et al. 2008). T6SS is also present in nonpathogenic bacteria such as the biocontrol strain $P$. fluorescens Pf-5 (Paulsen et al. 2005). We also have some evidence that Pf29Arp contains at least four T6SS clusters (unpublished results). The role of Pf29Arp T6SS and associated effectors in colonization of necrotic roots remains to be assessed.

In conclusion, the two-step infection process of roots by the take-all fungus provided strong support for the concept of pathorhizosphere. Indeed, changes in gene expression of Pf29Arp do not simply reflect the influence of either roots or $G$. graminis var. tritici alone. The set of genes triggered on necrotic roots gives evidence of an adaptative response of Pf29Arp to this environment. This phenomenon could explain the role of necrotic roots in the selection of some adapted rhizobacteria after a disease outbreak in wheat fields. However, other regulation levels such as post-transcriptional controls with the Gac/Rsm cascade (Kay et al. 2005) probably occurred in this environment.

\section{MATERIALS AND METHODS}

Plant growth assay.

Wheat seeds of Triticum aestivum cv. Talent were placed in sterile deionized water, sonicated $(40 \mathrm{~Hz}, 2 \mathrm{~min} 30 \mathrm{~s})$, surface sterilized for $5 \mathrm{~min}$ with a $2.5 \%$ hypochlorite solution, and rinsed five times with sterile deionized water for $5 \mathrm{~min}$. Then, seeds were soaked in $42^{\circ} \mathrm{C}$ preheated, deionized water for 10 min. Five seeds per plate were placed on LPGA medium (yeast extract at $5 \mathrm{~g} \mathrm{liter}^{-1}$ [Difco, Franklin Lakes, NJ, U.S.A.), peptone at $5 \mathrm{~g} \mathrm{liter}^{-1}$ from meat [Merck, Darmstadt, Germany], glucose at $5 \mathrm{~g} \mathrm{liter}^{-1}$ [Sigma-Aldrich, St. Louis], and agar at $15 \mathrm{~g} \mathrm{liter}^{-1}$ [VWR, Val de Fontenay, France]) and a 50- $\mu$ l drop of sterilized water was poured every $24 \mathrm{~h}$ on each seed. Germination and absence of microbial contamination were assessed after 2 days of incubation at $27^{\circ} \mathrm{C}$. Then, sterile tubes were filled with $10 \mathrm{ml}$ of MS media (Sigma-Aldrich) closed with a pierced closure. Germinated seed were sustained in the closure with roots descending into the liquid media. To preserve a gnotobiotical environment, the system was covered with larger sterile tubes and then was incubated at $15^{\circ} \mathrm{C}$ with a cycle of alternating $14 \mathrm{~h}$ of light and $10 \mathrm{~h}$ of darkness (irradiance $4 \mathrm{Wm}^{-2}$ ). After 5 days, seedlings were carefully collected and roots were rinsed with sterile deionized water. Each seedling was laid at the border of a 9-cm petri dish containing water agar $\left(30 \mathrm{~g} \mathrm{liter}^{-1}\right)$. A hole was previously made at the border and also in the lid of the dish to let the roots grow gnotobiotically inside and to let the leaf outside (Fig. 1). Each dish was closed with Parafilm M (Pechiney, Chicago), surrounded with an aluminum sheet, and placed inside a larger $15-\mathrm{cm}$ sterile dish to retain a sterile opaque environment. The plates were placed vertically in an incubator at $15^{\circ} \mathrm{C}$ with the leaf orientated in front and a cycle of alternating $14 \mathrm{~h}$ of light and $10 \mathrm{~h}$ of darkness.

\section{Fungal and bacterial root inoculations.}

The soilborne pathogenic fungus G. graminis var. tritici IV26/00 (Willocquet et al. 2008) was maintained on potato dextrose agar (PDA) (Merck) at $20^{\circ} \mathrm{C}$ for a week. The fungal inoculum consisted of $8-\mathrm{mm}^{3}$ plugs ( 2 by 2 by $2 \mathrm{~mm}$ ) cut from the colony edge of the growing filamentous $G$. graminis var. tritici. For each sterile seedling, three plugs were placed on the three seminal roots at $3 \mathrm{~cm}$ below the seed and incubated at $15^{\circ} \mathrm{C}$. Then, plugs were removed after $48 \mathrm{~h}$, allowing $G$. graminis var. tritici mycelium to grow along the root surface.
P. fluorescens Pf 29Arp (Chapon et al. 2002) was first grown on King's B medium (Pseudomonas $\mathrm{F}$ agar at $35 \mathrm{~g} \mathrm{liter}^{-1}$ and $1 \%$ glycerol) for two days at $27^{\circ} \mathrm{C}$. Then, one colony was picked up and suspended in $10 \mathrm{ml}$ of LPG overnight at $27^{\circ} \mathrm{C}$ under constant agitation $(150 \mathrm{rpm})$. The bacteria were centrifuged at 4,500 $\times g$ for $5 \mathrm{~min}$ and the pellet was washed once and resuspended in deionized water to obtain a suspension with an optical density at $600 \mathrm{~nm}=0.25\left(10^{8} \mathrm{CFU} \mathrm{ml}^{-1}\right)$. Fungal plugs were removed from the roots and two drops of $5 \mu \mathrm{l}$ $\left(10^{6}\right.$ cells $)$ were immediately deposited side by side on each root at $3 \mathrm{~cm}$ from the seed, right through the deposit of the fungal plug. Seedlings were then incubated at $15^{\circ} \mathrm{C}$.

Influence of roots and G. graminis var. tritici was followed at two stages of the $G$. graminis var. tritici infection process. Indeed, G. graminis var. tritici first grew on the wheat root surface as melanized ectotrophic "runner" hyphae; then, hyaline hyphae emerged and penetrated the root cortex and ultimately the stele, which led to necrotic roots (Freeman and Ward 2004). Therefore, we built up a bioassay in which the biocontrol strain Pf29Arp was inoculated on three distinct wheat roots environments: healthy $(\mathrm{H})$; early $G$. graminis var. tritici colonized (E), which correspond to the first stage of the $G$. graminis var. tritici infection process with a 2-day-old $G$. graminis var. tritici inoculation; and necrotic roots $(\mathrm{N})$, with a 5-day-old $G$. graminis var. tritici inoculation. For the three conditions, Pf29Arp was inoculated at day 12 on the in vitro growing root; therefore, 2 days after $G$. graminis var. tritici inoculation for $\mathrm{E}$ and 5 days after $G$. graminis var. tritici inoculation for $\mathrm{N}$ (Fig. 2). Controls for Pf29Arp effect and root disease assessments consisted of the same three conditions $(\mathrm{H}$, E, and N) without any Pf29Arp inoculation.

\section{Root disease quantification and observation.}

Disease was assessed for $\mathrm{E}$ and $\mathrm{N}$ conditions in the presence or absence of Pf29Arp inoculation and at 4, 5, and 7 days after $G$. graminis var. tritici inoculation. Disease incidence corresponded to the frequency of roots with a dark necrotic symptom (at least $1 \mathrm{~mm}$ in length) and disease severity corresponded to the length of dark necrosis. The observations were conducted on each of three roots of nine seedlings for each condition and independently repeat twice.

Fungal growth at the surface of the roots was studied by a binocular microscope and light microscopy of stained mycelium as outlined by Resendes and associates (2001). Each day following $G$. graminis var. tritici inoculation, three roots per treatment were sampled and cut into 2-cm-long segments (1 $\mathrm{cm}$ at each side of the fungal plug). Segments were fixed overnight in $50 \%$ ethanol, transferred to $5 \% \mathrm{KOH}$ (wt/vol), autoclaved for $15 \mathrm{~min}$ at $120^{\circ} \mathrm{C}$ to clear, rinsed in water, and, finally, placed in the stain at $50^{\circ} \mathrm{C}$ for $1 \mathrm{~h}$. The stain consisted of $0.1 \%$ Chlorazol Black E, $85 \%$ lactic acid, and glycerol $(1: 1: 1, \mathrm{vol} / \mathrm{vol} / \mathrm{vol})$. The stained segments were mounted and examined under a binocular microscope. Internal invasion of plant tissue by $G$. graminis var. tritici was also studied by another method using a modification of the above clearing and staining technique. Segments $(2 \mathrm{~cm}$ long) were fixed overnight in $50 \%$ ethanol, stained with Chlorazol Black E for 5 min, rinsed two times in sterile water, and then placed on a slide. Cross-sections of root segment were done every $1 \mathrm{~mm}$ under a binocular microscope $(\times 12)$ and segments were mounted and examined by light microscopy. These experiments were independently repeated three times.

\section{Bacterial population assessment.}

$P$. fluorescens Pf29Arp growth was monitored by dilution plating $20 \mathrm{~min}$ after bacterial inoculation and then every $24 \mathrm{~h}$ during 4 days. For this purpose, root fragments of $8 \mathrm{~mm}$ around 
Pf29Arp inoculation spot ( $3 \mathrm{~cm}$ below the seed) were cut for each treatment, suspended in $1 \mathrm{ml}$ of sterile water, and sonicated two times $(40 \mathrm{~Hz}, 3 \mathrm{~s})$. The bacterial suspension was 10 fold diluted and $10-\mu l$ aliquots of the dilution (three replicates per dilution) were plated on King B medium. Colonies were counted after incubation at $27^{\circ} \mathrm{C}$ for 2 days. For each treatment (absence or presence of G. graminis var. tritici and Pf29Arp), results were expressed in $\log _{10} \mathrm{CFU} \mathrm{cm} \mathrm{cm}^{-1}$ of roots as means of three biological replicates (three different plants) with two technical replicates per biological replicate.

To test equalities between experimental treatment for mean necrosis length and mean $\log _{10} \mathrm{CFU} \mathrm{cm}{ }^{-1}$ of roots, analysis of variance and Student's test were performed $(P=0.05)$. Equalities between experimental treatments for incidence were assessed by confidence interval of mean differences $(P=0.05)$.

\section{RNA extraction, amplification, and cDNA labeling.}

Eighteen root fragments of $8 \mathrm{~mm}$ each from six different plants were cut for each independent biological replicates of each treatment $(\mathrm{H}, \mathrm{E}$, and $\mathrm{N})$ suspended in $1 \mathrm{ml}$ of RNAlater (Ambion, Austin, TX, U.S.A.) and stored at $-20^{\circ} \mathrm{C}$. Suspension was sonicated two times $(40 \mathrm{~Hz}, 3 \mathrm{~s})$ and centrifuged $(6,000 \times g$, $5 \mathrm{~min}$ ). The pellet was resuspended with $100 \mu \mathrm{l}$ of supernatant to avoid loss of bacterial cells and total RNA from $P$. fluorescens Pf29Arp was extracted as described earlier (Barret et al. 2009). RNA yield was determined spectrophotometrically (Agilent, Santa Clara CA, U.S.A.) and RNA quality checked by the Bioanalyzer 2100 (Agilent). Total RNA was amplified through a method described earlier by Moreno-Paz and Parro (2006) based on a random priming approach with the T7 RNA polymerase using the reagents and components of the Message Amp amplified RNA (aRNA) kit (Ambion). aRNA (5 $\mu \mathrm{g})$ was labeled with the ChipShot Indirect Labeling and Clean-Up System (Promega Corp., Madison, WI, U.S.A.), and the CyDye (Cy3/Cy5) Reactive Dye Protocols for Post-Labeling Aminoallyl-cDNA (Amersham Biosciences, Piscataway, NJ, U.S.A.). The efficiency of Cy label incorporation into the cDNA and the quality and amounts of labeled cDNA was verified using a Nanodrop (Agilent).

To assess bias introduced by the amplification system, we hybridized amplified against unamplified RNA extracted from a 48-h-old culture of $P$. fluorescens Pf29Arp on a complete medium (Barret et al. 2009). Two technical replicates corresponding to a dye-swap were performed for this experiment and data were analyzed as described below.

\section{Microarray experiment and data analysis.}

Shotgun DNA microarrays were constructed from a PCRamplified gene library from $P$. fluorescens Pf29Arp as previously described (Barret et al. 2009). The array contained 14,000 PCR products representing approximately $80 \%$ of the Pf29Arp genome.

Hybridization was performed on a Ventana Discovery system (Ventana, Tucson, AZ, U.S.A.) for $8 \mathrm{~h}$ at $42^{\circ} \mathrm{C}$ using the OUEST-genopole transcriptomic facilities (IFR 140 GFAS, Rennes, France). Washes were performed manually at room temperature in two successive $1 \times$ Ribowash solutions (Ventana) followed by a wash in $0.1 \times \mathrm{SSC}(1 \times \mathrm{SSC}$ is $0.15 \mathrm{M} \mathrm{NaCl}$ plus $0.015 \mathrm{M}$ sodium citrate) at room temperature. Fluorescent images of the microarrays, which were generated with a Genepix 4000B scanner, were then analyzed with the Genepix Pro analysis software (v6.0; Molecular Devices, Sunnyvale, CA, U.S.A.).

A loop design was applied for running the microarrays to minimize the variance of contrasts of interest with a convenient number of arrays. Samples $(\mathrm{H}, \mathrm{E}$, and $\mathrm{N})$ were hybridized in pairs ( $E$ versus $H, N$ versus $H$, and $N$ versus $E$ ) on three different slides. For each pair, three independent biological replicates and two technical replicates (dye-swap) were performed. Thus, in total, 18 slides were hybridized and compared. Raw data from microarray hybridization, exported from GenePix suites 6.0, was imported into LIMMA (Smyth and Speed 2003) with annotation and spot types. Spots with a negative flag value, a signal-tonoise ratio (SNR) threshold $\leq 2$ and an irregular aspect were assigned a weight of 0 in the subsequent analysis. Signal intensities were normalized using a print-tip group Loess normalization (within-array normalization). Statistical values for gene expression of sample pairs were calculated after fitting a mixedmodel analysis of variance (model provided by LIMMA) in R Software by using the LIMMA package (Smyth 2004). This statistical analysis permitted us to take into account the negative correlation which exists between technical replicates (dye-swap pairs). Moreover, the method uses empirical Bayes methods to moderate the standard deviation between genes (Milliken and Johnson 1992). The adjusted $P$ value was then assessed for each gene by controlling the false discovery rate using the Benjamini Hochberg method (Benjamini and Hochberg 1995). To investigate which levels of factor differ when the global $F$ test from our model is significant $(P<0.01)$, pairwise comparisons were made by using planed contrasts (E versus $\mathrm{H}, \mathrm{N}$ versus $\mathrm{H}$, and $\mathrm{N}$ versus E). Three lists of differential genes were then obtained with $1 \%$ of false positive in each list.

\section{Clones sequencing.}

Sequencing was carried out by GATC Biotech (Konstanz, Germany). Sequences were analyzed using Bioedit software, and Blast2go (Conesa et al. 2005) was used for searching for similarities on the Pseudomonas genome database (Winsor et al. 2009) and on the nonredundant protein and DNA sequence database at the National Center for Biotechnology Information (Pruitt et al. 2005).

\section{Real-time RT-PCR.}

Real-time PCR analyses were performed on some selected differentially expressed genes. The expression stability of five constitutive genes (Supplementary Table S3) was calculated using geNorm (Vandesompele et al. 2002). Two of them ( $p p k A$ and quiP, encoding a serine/threonine protein kinase and a protein related to penicillin acylase, respectively) were chosen for data normalization. This approach relies on the principle that the expression ratio of two ideal control genes is constant in all the samples, independent of the experimental conditions. Genes with the lowest gene expression stability (M) have the most stable expression while the highest $\mathrm{M}$ value indicates the least stable expression (Vandesompele et al. 2002). aRNA (500 ng) used to hybridize the array slides was reverse transcribed using the ImProm-I Reverse Transcription System (Promega Corp.). qPCR reactions $(25 \mu \mathrm{l})$ containing $2 \mu \mathrm{l}$ of cDNA, 300 $\mathrm{nM}$ each primer, $1 \times$ iTaq SYBR Green Supermix (Bio-Rad, Hercules, CA, U.S.A.) were performed on the ABI Prism s7700 sequence detection system. Amplification conditions were initial denaturation at $95^{\circ} \mathrm{C}$ for $5 \mathrm{~min}$ and 40 cycles of $95^{\circ} \mathrm{C}$ for $30 \mathrm{~s}$ and $60^{\circ} \mathrm{C}$ for $30 \mathrm{~s}$. Standard curve was performed for each gene on four different dilutions of cDNA products. A dissociation curve was constructed at the end of each run in order to detect nonspecific amplifications. The $\mathrm{Ct}$ values were transformed to quantities by using standard curves. The expression level of each gene of interest was calculated by dividing the quantities for each sample by the appropriate geNorm normalization factor.

\section{ACKNOWLEDGMENTS}

We thank C. Chevalier from the Biogenouest transcriptomic facilities (INSERM U533, Nantes); A. Le Cam and J. Montfort from Institut Na- 
tional de la Recherche Agronomique (INRA)-Station Commune de Recherches en Ichtyophysiologie, Biodiversité et Environment transcriptomic facilities (IFR140 GFAS, Rennes) A. Deveau and F. Martin (UMR1136, INRA Nancy) for their useful suggestions; D. Tagu, F. Val (UMR BiO3P, INRA, Rennes), C. Baysse (UMR CNRS 6026, Rennes), and I. Couée (UMR 6553 ECOBIO, Rennes) for their comments; and M. Dow for having carefully read the manuscript. This work was supported by INRA Plant Health and Environment division, Région Bretagne, and the Ecologie pour la gestion des écosystèmes et de leurs ressources research program.

\section{LITERATURE CITED}

Andrade, G., Mihara, K. L., Linderman, R. G., and Bethlenfalvay, G. J. 1997. Bacteria from rhizosphere and hyphosphere soils of different arbuscular-mycorrhizal fungi. Plant Soil 192:71-79.

Appel, H. 1992. Phenolics in ecological interactions-the importance of oxidation. J. Chem. Ecol. 19:1521-1552.

Barnett, S. J., Singleton, I., and Ryder, M. 1999. Spatial variation in populations of Pseudomonas corrugata 2140 and pseudomonads on take-all diseased and healthy root systems of wheat. Soil Biol. Biochem. 31:633-636.

Barret, M., Frey-Klett, P., Boutin, M., Guillerm-Erckelboudt, A. Y., Martin, F., Guillot, L., and Sarniguet, A. 2009. The plant pathogenic fungus Gaeumannomyces graminis var. tritici improves bacterial growth and triggers early gene regulations in the biocontrol strain Pseudomonas fluorescens Pf 29Arp. New Phytol. 181:435-447.

Benjamini, Y., and Hochberg, Y. 1995. Controlling the false discovery rate: A practical and powerful approach to multiple testing. J. Roy. Stat. Soc. Ser. B 57:289-300.

Bertin, C., Yang, X. H., and Weston, L. A. 2003. The role of root exudates and allelochemicals in the rhizosphere. Plant Soil 256:67-83.

Bloemberg, G. V., Wijfjes, A. H. M., Lamers, G. E. M., Stuurman, N., and Lugtenberg, B. J. J. 2000. Simultaneous imaging of Pseudomonas fluorescens WCS365 populations expressing three different autofluorescent proteins in the rhizosphere: New perspectives for studying microbial communities. Mol. Plant-Microbe Interact. 13:1170-1176.

Blumer, C., and Haas, D. 2000. Mechanism, regulation, and ecological role of bacterial cyanide biosynthesis. Arch. Microbiol. 173:170-177.

Bolwerk, A., Lagopodi, A. L., Wijfjes, A. H. M., Lamers, G. E. M., ChinA-Woeng, T. F. C., Lugtenberg, B. J. J., and Bloemberg, G. V. 2003. Interactions in the tomato rhizosphere of two Pseudomonas biocontrol strains with the phytopathogenic fungus Fusarium oxysporum f. sp. radicis-lycopersici. Mol. Plant-Microbe Interact. 16:983-993.

Buell, C. R., and Anderson, A. J. 1992. Genetic-analysis of the aggA locus involved in agglutination and adherence of Pseudomonas putida, a beneficial fluorescent pseudomonad. Mol. Plant-Microbe Interact. 5:154-162.

Chapon, A., Guillerm, A. Y., Delalande, L., Lebreton, L., and Sarniguet, A. 2002. Dominant colonisation of wheat roots by Pseudomonas fluorescens $\mathrm{Pf} 29 \mathrm{~A}$ and selection of the indigenous microflora in the presence of the take-all fungus. Eur. J. Plant Pathol. 108:449-459.

Chin-A-Woeng, T. F. C., de Priester, W., van der Bij, A. J., and Lugtenberg, B. J. J. 1997. Description of the colonization of a gnotobiotic tomato rhizosphere by Pseudomonas fluorescens biocontrol strain WCS365, using scanning electron microscopy. Mol. Plant-Microbe Interact. 10:79-86.

Cody, L. S., Pritchett, C. L., Jones, A. K., Carterson, A. J., Jackson, D., Frisk, A., Wolfgang, M. C., and Schurr, M. J. 2009. Pseudomonas aeruginosa AlgR controls cyanide production in an AlgZ-dependent manner. J. Bacteriol. 191(9):2993-3002.

Conesa, A., Gotz, S., Garcia-Gomez, J. M., Terol, J., Talon, M., and Robles, M. 2005. Blast2GO: A universal tool for annotation, visualization and analysis in functional genomics research. Bioinformatics 21:3674-3676.

Cook, R. J., and Rovira, A. D. 1976. The role of bacteria in the biological control of Gaeumannomyces graminis by suppressive soils. Soil Biol. Biochem. 8:269-273.

Curl, E. A., and Truelove, B. 1986. The Rhizosphere. Springer-Verlag, Berlin.

de Boer, W., Folman, L. B., Summerbell, R. C., and Boddy, L. 2005. Living in a fungal world: Impact of fungi on soil bacterial niche development. FEMS (Fed. Mol. Microbiol. Soc.) Microbiol. Rev. 29:795-811.

Denison, R. F., Bledsoe, C., Kahn, M., O’Gara, F., Simms, E. L., and Thomashow, L. S. 2003. Cooperation in the rhizosphere and the "free rider" problem. Ecology 84:838-845.

Deveau, A., Palin, B., Delaruelle, C., Peter, M., Kohler, A., Pierrat, J. C., Sarniguet, A., Garbaye, J., Martin, F., and Frey-Klett, P. 2007. The mycorrhiza helper Pseudomonas fluorescens BBc6R8 has a specific priming effect on the growth, morphology and gene expression of the ectomycorrhizal fungus Laccaria bicolor S238N. New Phytol. 175:743-755. de Weert, S., Vermeiren, H., Mulders, I. H. M., Kuiper, I., Hendrickx, N. Bloemberg, G. V., Vanderleyden, J., De Mot, R., and Lugtenberg, B. J. J. 2002. Flagella-driven chemotaxis towards exudate components is an important trait for tomato root colonization by Pseudomonas fluorescens. Mol. Plant-Microbe Interact. 15:1173-1180.

de Weert, S., Kuiper, I., Lagendijk, E. L., Lamers, G. E. M., and Lugtenberg, B. J. J. 2004. Role of chemotaxis toward fusaric acid in colonization of hyphae of Fusarium oxysporum f. sp. radicis-lycopersici by Pseudomonas fluorescens WCS365. Mol. Plant-Microbe Interact. 17:1185-1191.

Filloux, A., Hachani, A., and Bleves, S. 2008. The bacterial type VI secretion machine: Yet another player for protein transport across membranes. Microbiology 154:1570-1583.

Freeman, J., and Ward, E. 2004. Gaeumannomyces graminis, the take-all fungus and its relatives. Mol. Plant Pathol. 5:235-252.

Frey-Klett, P., Chavatte, M., Clausse, M. L., Courrier, S., Le Roux, C., Raaijmakers, J., Martinotti, M. G., Pierrat, J. C., and Garbaye, J. 2005. Ectomycorrhizal symbiosis affects functional diversity of rhizosphere fluorescent pseudomonads. New Phytol. 165:317-328.

Gao, J. J., Lee, K., Zhao, M., Qiu, J., Zhan, X. M., Saxena, A., Moore, C. J., Cohen, S. N., and Georgiou, G. 2006. Differential modulation of $E$. coli mRNA abundance by inhibitory proteins that alter the composition of the degradosome. Mol. Microbiol. 61:394-406.

Ghiglione, J. F., Gourbiere, F., Potier, P., Philippot, L., and Lensi, R. 2000. Role of respiratory nitrate reductase in ability of Pseudomonas fluorescens YT101 to colonize the rhizosphere of maize. Appl. Environ. Microbiol. 66:4012-4016.

Haas, D., and Defago, G. 2005. Biological control of soil-borne pathogens by fluorescent pseudomonads. Nat. Rev. Microbiol. 3:307-319.

Hammerschmidt, R. 2005. Phenols and plant-pathogen interactions: The saga continues. Physiol. Mol. Plant Pathol. 66:77-78.

Jacob-Dubuisson, F., Locht, C., and Antoine, R. 2001. Two-partner secretion in Gram-negative bacteria: A thrifty, specific pathway for large virulence proteins. Mol. Microbiol. 40:306-313.

Jacob-Dubuisson, F., Fernandez, R., and Coutte, L. 2004. Protein secretion through autotransporter and two-partner pathways. Biochim. Biophys. Acta Mol. Cell Res. 1694:235-257.

Jamali, F., Sharifi-Tehrani, A., Lutz, M. P., and Maurhofer, M. 2009. Influence of host plant genotype, presence of a pathogen, and coinoculation with Pseudomonas fluorescens strains on the rhizosphere expression of hydrogen cyanide and 2,4-diacetylphloroglucinol biosynthetic genes in P. fluorescens biocontrol strain CHA0. Microb. Ecol. 57:267-275

Jungst, A., and Zumft, W. G. 1992. Interdependence of respiratory NO reduction and nitrite reduction revealed by mutagenesis of nirQ, a novel gene in the denitrification gene-cluster of Pseudomonas stutzeri. FEBS (Fed. Eur. Biochem. Soc.) Lett. 314:308-314.

Kamilova, F., Kravchenko, L. V., Shaposhnikov, A. I., Azarova, T., Makarova, N., and Lugtenberg, B. J. J. 2006a. Organic acids, sugars, and L-tryptophane in exudates of vegetables growing on stonewool and their effects on activities of rhizosphere bacteria. Mol. Plant-Microbe Interact. 19:250-256.

Kamilova, F., Kravchenko, L. V., Shaposhnikov, A. I., Makarova, N., and Lugtenberg, B. J. J. 2006b. Effects of the tomato pathogen Fusarium oxysporum f. sp. radicis-lycopersici and of the biocontrol bacterium Pseudomonas fluorescens WCS365 on the composition of organic acids and sugars in tomato root exudate. Mol. Plant-Microbe Interact. 19:1121-1126.

Kay, E., Dubuis, C., and Haas, D. 2005. Three small RNAs jointly ensure secondary metabolism and biocontrol in Pseudomonas fluorescens CHA0. Proc. Nat. Acad. Sci. U.S.A. 102(47):17136-17141.

Kloepper, J. W., Leong, J., Teintze, M., and Schroth, M..N. 1980. Pseudomonas siderophores-a mechanism explaining disease-suppressive soils. Curr. Microbiol. 4:317-320.

Kohlmeier, S., Smits, T. H. M., Ford, R. M., Keel, C., Harms, H., and Wick, L. Y. 2005. Taking the fungal highway: Mobilization of pollutantdegrading bacteria by fungi. Environ. Sci. Technol. 39:4640-4646.

Laville, J., Blumer, C., Von Schroetter, C., Gaia, V., Defago, G., Keel, C., and Haas, D. 1998. Characterization of the hcnABC gene cluster encoding hydrogen cyanide synthase and anaerobic regulation by ANR in the strictly aerobic biocontrol agent Pseudomonas fluorescens CHAO. J. Bacteriol. 180:3187-3196.

Lee, K. S., Zhan, X. M., Gao, J. J., Ji, Q., Feng, Y. A., Meganathan, R., Cohen, S. N., and Georgiou, G. 2003. RraA: A protein inhibitor of RNase E activity that globally modulates RNA abundance in E. coli. Cell. 114:623-634.

Lee, M., Yeom, J. H., Sim, S. H., Ahn, S., and Lee, K.S. 2009. Effects of Escherichia coli RraA orthologs of Vibrio vulnicus on the ribonucleolytic activity of RNase E in vivo. Curr. Microbiol. 58:349-353.

Locht, C., Bertin, P., Menozzi, F. D., and Renauld, G. 1993. The filamentous hemagglutinin, a multifaceted adhesin produced by virulent Bordetella spp. Mol. Microbiol. 9:653-660. 
Lugtenberg, B. J. J., Dekkers, L., and Bloemberg, G. V. 2001. Molecular determinants of rhizosphere colonization by Pseudomonas. Annu. Rev. Phytopathol. 39:461-490.

Mark, G. L., Dow, J. M., Kiely, P. D., Higgins, H., Haynes, J., Baysse, C. Abbas, A., Foley, T., Franks, A., Morrissey, J., and O'Gara, F. 2005. Transcriptome profiling of bacterial responses to root exudates identifies genes involved in microbe-plant interactions. Proc. Nat. Acad. Sci. U.S.A. 102:17454-17459.

Matilla, M. A., Espinosa-Urgel, M., Rodriguez-Herva, J. J., Ramos, J. L., and Ramos-Gonzalez, M. I. 2007. Genomic analysis reveals the major driving forces of bacterial life in the rhizosphere. Genome Biol. 8(9)

Mattinen, L., Somervuo, P., Nykyri, J., Nissinen, R., Kouvonen, P., Corthals, G., Auvinen, P., Aittamaa, M., Valkonen, J. P. T., and Pirhonen, M.. 2008. Microarray profiling of host-extract-induced genes and characterization of the type VI secretion cluster in the potato pathogen $\mathrm{Pec}$ tobacterium atrosepticum. Microbiology 154:2387-2396.

Milliken, G. A., and Johnson, D. E. 1992. Designed Experiments. Analysis of Messy Data, Volume 1. Chapman and Hall, New York.

Moreno-Paz, M., and Parro, V. 2006. Amplification of low quantity bacterial RNA for microarray studies: Time-course analysis of Leptospirillum ferrooxidans under nitrogen-fixing conditions. Environ. Microbiol. 8:1064-1073

Mougous, J. D., Cuff, M. E., Raunser, S., Shen, A., Zhou, M., Gifford, Goodman, A. L., Joachimiak, G., Ordonez, C. L., Lory, S., Walz, T., Joachimiak, A., and Mekalanos, J. J. 2006. A virulence locus of Pseudomonas aeruginosa encodes a protein secretion apparatus. Science 312:1526-1530.

Nicholson, R. L., and Hammerschmidt, R. 1992. Phenolic-compounds and their role in disease resistance. Annu. Rev. Phytopathol. 30:369-389.

Nishijyo, T., Haas, D., and Itoh, Y. 2001. The CbrA-CbrB two-component regulatory system controls the utilization of multiple carbon and nitrogen sources in Pseudomonas aeruginosa. Mol. Microbiol. 40:917-931.

Paulsen, I. T., Press, C. M., Ravel, J., Kobayashi, D. Y., Myers, G. S., Mavrodi, D. V., DeBoy, R. T., Seshadri, R., Ren, Q., Madupu, R., Dodson, R. J., Durkin, A. S., Brinkac, L. M., Daugherty, S. C., Sullivan, S. A., Rosovitz, M. J., Gwinn, M. L., Zhou, L., Schneider, D. J., Cartinhour, S. W., Nelson, W. C., Weidman, J., Watkins, K., Tran, K., Khouri, H., Pierson, E. A., Pierson L. S., Thomashow, L. S., and Loper, J. E. 2005. Complete genome sequence of the plant commensal Pseudomonas fluorescens Pf-5. Nat. Biotechnol. 23:873-878.

Philippot, L., Clays-Josserand, A., and Lensi, R. 1995. Use of tn5 mutants to assess the role of the dissimilatory nitrite reductase in the competitive abilities of 2 Pseudomonas strains in soil. Appl. Environ. Microbiol. 61:1426-1430.

Pruitt, K. D., Tatusova, T., and Maglott, D. R. 2005. NCBI Reference Sequence (RefSeq): A curate non-redundant sequence database of genomes, transcript and proteins. Nucleic Acids Res. 33:D501-D504.

Pukatzki, S., Ma, A. T., Revel, A. T., Sturtevant, D., and Mekalanos, J. J. 2007. Type VI secretion system translocates a phage tail spike-like protein into target cells where it cross-links actin. Proc. Nat. Acad. Sci. U.S.A. 104:15508-15513.

Pukatzki, S., McAuley, S. B., and Miyata, S. T. 2009. The type VI secretion system: Translocation of effectors and effector-domains. Curr. Opin. Microbiol. 12:11-17.

Rainey, P. B. 1999. Adaptation of Pseudomonas fluorescens to the plant rhizosphere. Environ. Microbiol. 1:243-257.

Ramos-Gonzalez, M. I., Campos, M. J., and Ramos, J. L. 2005. Analysis of Pseudomonas putida KT2440 gene expression in the maize rhizosphere: In vitro expression technology capture and identification of root-activated promoters. J. Bacteriol. 187:4033-4041.

Rengel, Z., Graham, R. D., and Pedler, J. F. 1994. Time-course of biosynthesis of phenolics and lignin in roots of wheat genotypes differing in manganese efficiency and resistance to take-all fungus. Ann. Bot. 74:471-477.

Resendes, C. M., Geil, R. D., and Guinel, F. C. 2001. Mycorrhizal development in a low nodulating pea mutant. New Phytol. 150:563-572.

Rodriguez-Navarro, D. N., Dardanelli, M. S., and Ruiz-Sainz, J. E. 2007. Attachment of bacteria to the roots of higher plants. FEMS (Fed. Eur. Microbiol. Soc.) Microbiol. Lett. 272:127-136.

Rojas, C. M., Ham, J. H., Deng, W. L., Doyle, J. J., and Collmer, A. 2002. HecA, a member of a class of adhesins produced by diverse pathogenic bacteria, contributes to the attachment, aggregation, epidermal cell killing, and virulence phenotypes of Erwinia chrysanthemi EC16 on Nicotiana clevelandii seedlings. Proc. Nat. Acad. Sci. U.S.A. 99:13142-13147.

Sanguin, H., Kroneisen, L., Gazengel, K., Kyselková, M., Remenant, B.,
Prigent-Combaret, C., Grundmann, G. L., Sarniguet, A., and MoënneLoccoz, Y. 2008. Development of a 16S rRNA microarray approach for the monitoring of rhizosphere Pseudomonas populations associated with the decline of take-all disease of wheat. Soil Biol. Biochem. 40:1028 1039 .

Sari, E., Etebarian, H. R., and Aminian, H. 2008. Effects of Pseudomonas fluorescens $\mathrm{CHA} 0$ on the resistance of wheat seedling roots to the takeall fungus Gaeumannomyces graminis var. tritici. Plant Prod. Sci. 11:298-306.

Sarniguet, A., Lucas, P., Lucas, M., and Samson, R. 1992. Soil conduciveness to take-all of wheat-influence of the nitrogen fertilizers on the structure of populations of fluorescent pseudomonads. Plant Soil 145:29-36.

Sarniguet, A., Kraus, J., Henkels, M. D., Muehlchen, A. M., and Loper J.E. 1995. The sigma factor sigma s affects antibiotic production and biological control activity of Pseudomonas fluorescens Pf-5. Proc. Nat. Acad. Sci. U.S.A. 92:12255-12259.

Sarniguet, A., Lucas, P., Guillerm, A. Y., De Vos, D., and Cornelis, P. 1997. Towards the use of fluorescent spp. Pseudomonas as bioindicators of soil conduciveness to take-all of wheat. Pages 413-416 in: Plant Growth Promoting Rhizobacteria: Present Status and Future Prospects. O. Ogoshi, K. Kobayashi, Y. Homma, F. Kodama, N. Kondo, and S. Akino. Organisation for Economic Co-operation and Development, Paris.

Sarniguet, A., Boutin, M., Guillerm-Erckelboudt, A. Y., and Barret, M. 2006. Three mechanisms for the biocontrol activity of Pseudomonas fluorescens Pf29A against the plant pathogenic fungus Gaeumannomyces graminis var. tritici. In: 7th Int. Workshop Plant Growth Promoting Rhizobacteria. Noordwijkerhout, The Netherlands.

Simons, M., vanderBij, A. J., Brand, I., deWeger, L. A., Wijffelman, C. A., and Lugtenberg, B. J. J. 1996. Gnotobiotic system for studying rhizosphere colonization by plant growth-promoting Pseudomonas bacteria. Mol. Plant-Microbe Interact. 9:600-607.

Simons, M., Permentier, H. P., deWeger, L. A., Wijffelman, C. A., and Lugtenberg, B. J. J. 1997. Amino acid synthesis is necessary for tomato root colonization by Pseudomonas fluorescens strain WCS365. Mol. Plant-Microbe Interact. 10:102-106.

Smyth, G. 2004. Linear models and empirical Bayes methods for assessing differential expression in microarray experiments. Stat. Appl. Genet. Mol. Biol. 3(1)

Smyth, G. K., and Speed, T. 2003. Normalization of cDNA microarray data. Methods 31:265-273.

Tarkka, M. T., Sarniguet, A., and Frey-Klett, P. 2009. Inter-kingdom encounters: Recent advances in molecular bacterium-fungus interactions. Curr. Genet. 55:233-243.

Vandesompele, J., De Preter, K., Pattyn, F., Poppe, B., Van Roy, N., De Paepe, A., and Speleman, F. 2002. Accurate normalization of real-time quantitative RT-PCR data by geometric averaging of multiple internal control genes. Genome Biol. 3:RESEARCH0034.

van Loon, L. C., Bakker, P. A., and Pieterse, C. M. 1998. Systemic resistance induced by rhizosphere bacteria. Annu. Rev. Phytopathol. 36:453-483.

Voisard, C., Keel, C., Haas, D., and Defago, G. 1989. Cyanide production by Pseudomonas fluorescens helps suppress black root rot of tobacco under gnotobiotic conditions. EMBO (Eur. Mol. Biol. Organ.) J. 8:351-358.

Wargo, M. J., Szwergold, B. S., and Hogan, D. A. 2008. Identification of two gene clusters and a transcriptional regulator required for Pseudomonas aeruginosa glycine betaine catabolism. J. Bacteriol. 190:2690-2699.

Willocquet, L., Lebreton, L., Sarniguet, A., and Lucas, P. 2008. Quantification of within-season focal spread of wheat take-all in relation to pathogen genotype and host spatial distribution. Plant Pathol. 57:906915.

Winsor, G. L., Van Rossum, T., Lo, R., Khaira, B., Whiteside, M. D., Hancock, R. E., and Brinkman, F. S. 2009. Pseudomonas Genome Database: Facilitating user-friendly, comprehensive comparisons of microbial genome. Nucleic Acids Res. 37:483-488.

Wu, H. Y., Chung, P. C., Shih, H. W., Wen, S. R., and Lai, E. M. 2008. Secretome analysis uncovers an hcp-family protein secreted via a type VI secretion system in Agrobacterium tumefaciens. J. Bacteriol. 190:2841-2850.

Yeom, J. H., Go, H., Shin, L., Kim, H. L., Han, S. H., Moore, C. J., Bae, J., and Lee, K. S. 2008. Inhibitory effects of RraA and RraB on RNase E-related enzymes imply conserved functions in the regulated enzymatic cleavage of RNA. FEMS (Fed. Eur. Microbiol. Soc.) Microbiol. Lett. 285:10-15.

Zhang, X. X., and Rainey, P. B. 2008. Dual involvement of CbrAB and NtrBC in the regulation of histidine utilization in Pseudomonas fluorescens SBW25. Genetics 178:185-195. 